\title{
Echnaton, seine Leute und die Sprache
}

\author{
Ein politisch induzierter Sprachwandel in der Amarnazeit
}

\begin{abstract}
Amenhotep IV/Akhenaten (1351-1334 BC), a king of the Egyptian 18th Dynasty, undertook many reforms during his reign. He reformed religion, art and architecture. The language of that time shows a sudden change. The Late Egyptian innovations of everyday language, which were rarely used in the decorative texts before the Amarna period, gained momentum in the Amarna texts. Astonishingly, those innovations were much less used in the post-Amarna period. This change of language in the Amarna period is interpreted in this research as a political act attributed to King Akhenaten, or to a new layer of officials who could not master classical Egyptian language.
\end{abstract}

\section{Einleitung}

Dem Kenner der ägyptischen Sprache fällt auf, dass sich während der Amarnazeit (ca. 1346-1332 v. Chr.) ${ }^{1}$ eine große Anzahl von neuägyptischen Sprachinnovationen zeigt. Diese treten nicht nur in den Alltagstexten auf, ${ }^{2}$ wie es seit dem

1 Für die Regierungsdaten wird von Beckerath (1997) herangezogen. Bei der Transliteration der ägyptischen Texte wird hier historisch verfahren. Phonetische Änderungen, wie z. B. /t / $>/ t /$, werden in der Umschrift nicht berücksichtigt. Geschweifte Klammern \{ \} geben zu Tilgendes, eckige [ ] Zerstörtes an. Die runden ( ) stehen für ergänzende Zeichen, welche im Originaltext nicht existieren und die spitzen $<>$ für Eingefügtes, = trennt das Suffixpronomen vom Bezugswort ab.

2 Nach Junge (1984) Sp. 1176-1211; (1985) 17-34 sind vier Register der Schriftsprache zu unterscheiden, die als Ganzes das jeweilige Sprachsystem ausmachen: Alltags-/nicht-literarische Texte, literarische Texte, Dekorumstexte und theologische Texte, s. Junge (2008) 16f. Die Alltagstexte sind in der gesellschaftlichen Hierarchie der Sprachnormen niedrig angesiedelt und stehen daher vielen Innovationen der Umgangssprache offen, wie z. B. Korrespondenzen. Diese sprachlichen Neuerungen können im Laufe der Zeit in andere höhere Sprachnormen übernommen werden, Junge (1985) 22. Die literarischen Texte stellen ein Korpus mit eigener Sprachnorm dar, die konservative, Übergangs- und einige alltagssprachliche Formen beheimatet, s. Goldwasser (1999) 314. Die Dekorumstexte, wie z. B. Stelentexte sowie Grab- und Tempel-

Anmerkung: Der vorliegende Artikel basiert auf meiner Magisterarbeit, die im März 2014 bei Prof. Dr. Friedhelm Hoffmann am Institut für Ägyptologie und Koptologie der Ludwig-Maximilians-Universität München eingereicht wurde.

2 Open Access. () 2018 Essam Hammam, publiziert von De Gruyter. (cc) BY-NC-ND Dieses Werk ist lizenziert unter der Creative Commons Attribution-NonCommercial-NoDerivatives 4.0 Lizenz.

https://doi.org/10.1515/9783110601268-004 
Ende der 17. Dynastie (ca. 1645-1550 v. Chr.) der Fall ist, sondern kommen auch in den Dekorumstexten regelmäßig vor. Einige dieser Neuerungen, und das ist besonders auffällig, finden in den Dekorumstexten der Vor- und Nachamarnazeit nur selten Verwendung. Offensichtlich ist in der Amarnazeit die Sprache der Alltagstexte in die Dekorumstexte übernommen worden. Angesichts der sonst strengen Trennung von Alltags- und Dekorumssprache ist das erklärungsbedürftig. Möglicherweise hängt die Neuformierung der Sprachregister mit den Reformen Amenophis’ IV./Echnatons (ca. 1351-1334 v. Chr.) in Religion, Kunst und Architektur zusammen.

In der vorliegenden Abhandlung wird versucht, dieses Phänomen genauer zu betrachten, indem Texte der Vor-, Amarna- und Nachamarnazeit analysiert werden. In erster Linie wird der Frage nachgegangen, ob, und falls ja, wie viele neuägyptische Innovationen die Dekorumstexte von der Zeit Amenophis' III. (ca. 1388-1351/50 v. Chr.) bis einschließlich Ramses II. (ca. 1279-1213 v. Chr.) aufweisen. Im weiteren Verlauf wird geklärt, ob, und falls ja, inwieweit diese Könige die Wahl der Sprachnorm beeinflussen konnten. Im Rahmen dieser Arbeit wird die Untersuchung jedoch nur auf die königlichen Stelentexte beschränkt, da sie ein Korpus darstellen, das sprachlich einheitlich ist. Als Vergleichsmaterial sind Briefe von Privatpersonen sehr geeignet, da sie der gesprochenen Sprache am ähnlichsten sind (s. o. Anm. 2). Bei der Auswahl der Texte wurde darauf geachtet, dass zwei Textsorten vertreten sind, in denen auf der einen Seite ein Festhalten an der klassischen Sprache und ihren Normen erwartet ist, auf der anderen Seite von einem ziemlich freien Umgang mit der Sprache und daher von einer ungezwungenen und ungekünstelten Sprache ausgegangen wird.

Die Texte der ausgewählten Zeitphase wurden noch nie diachron abgehandelt. Kroeber (1970) hört bei seiner Dissertation über die Neuägyptizismen vor der Amarnazeit bei dem König Amenophis III. auf. In einem Artikel behandelt Kruchten den Übergang vom Mittelägyptischen zum Neuägyptischen in der Zeit vom Ende der 17. Dynastie bis zur Amarnazeit. ${ }^{3}$ Die Untersuchung beschränkt sich jedoch auf bestimmte sprachliche Phänomene in Texten, die in der Alltagssprache geschrieben sind. ${ }^{4}$ Behnk (1924) veröffentlichte eine de-

inschriften, sind in der Regel Hieroglyphentexte, die die traditionelle Schriftsprache bevorzugen und einen Widerstand gegen Neuerungen zeigen, Junge (2008) $16 \mathrm{f}$. Theologische und liturgische Texte sind sehr konservativ und gestatten kaum sprachliche Änderungen, können sich jedoch aus Abschriften von Texten aus der gesamten ägyptischen Sprachgeschichte zusammensetzen, Quack (2013) 40-45.

3 Kruchten (1999) 1-97.

4 Kruchten (1999) $5 \mathrm{f}$. 
skriptive Grammatik über die Texte der Amarnazeit, die sich lediglich mit der Häufigkeit der neuägyptischen Sprachformen in allen Textgattungen in der Amarnazeit befasst. Israeli setzt sich in einem Beitrag mit Verbalformen und Verbal- und Nominalphrasen in den Texten der Amarnazeit auseinander, ohne dass sie aber versucht, diese sprachgeschichtlich zuzuordnen. ${ }^{5}$

Die Sprache der Amarnazeit wurde mehr oder weniger explizit im Übergangsfeld vom Mittel- zum Neuägyptischen angesiedelt, oft ohne soziolinguistische Differenzierung. Während Erman, Korostovcev, Winand und Junge Texte der Amarnazeit in ihren neuägyptischen Grammatiken heranziehen, schließen andere wie Černý \& Groll und Frandsen diese Texte komplett aus und wenden sich den nichtliterarischen Texten der 19.-21. Dynastie (ca. 1292-946/45 v. Chr.) zu. ${ }^{6}$ In der oben erwähnten Grammatik zeigt Behnk, welche neuägyptischen Merkmale in den Texten der Amarnazeit zu finden sind. In seiner Studie schließt Kroeber die Texte dieser Zeit nicht ein, was andeuten kann, dass er die Sprache der Amarnazeit schon als Neuägyptisch betrachtete. ${ }^{7}$ Für Junge sind die Texte der Amarnazeit entweder Spätmittelägyptisch oder MedioNeuägyptisch. ${ }^{8}$ Silverman unterscheidet zwischen der Sprache der religiösen und amtlichen Texte und derjenigen der Briefe. Die erste ist eine künstliche Sprache, die sich von der Sprache der Voramarnazeit unterscheidet und die von Echnaton selbst für die Niederschrift seines Glaubens und seiner Doktrinen geschaffen wurde. Die Sprache der Briefe kann man als eine Entwicklungsphase zwischen derjenigen der Briefe der 18. und der 19. und 20. Dynastie sehen. ${ }^{9}$

Das Verhältnis zwischen der Standard- und der Alltagssprache wird von Jansen-Winkeln, Goldwasser und Nagai mehr oder weniger ausführlich angeschnitten. ${ }^{10}$ Es wird auch die Frage berührt, wie die Umgangssprache die Hochsprache beeinflussen oder sogar ersetzen kann. Goldwasser z. B. erwähnt zwei Arten, die hier von Bedeutung sind: Die erste ist das langsame Eindringen der gesprochenen Sprache in die geschriebene Sprache, das seit der 1. Zwischenzeit festzustellen ist. Die zweite ist der amtliche Weg durch den Machthaber. ${ }^{11}$

5 Israeli (1981-1982) 279-304.

6 Erman (1933) §§ 1f.; Korostovcev (1973) 4; Winand (1992) 23-25; Junge (2008) 15 f.; Černý \& Groll (1993) XLIX f.; Frandsen (1974), VII.

7 Kroeber (1970) XVI-XVIII.

8 Junge (1985) 28.

9 Silverman (1991) 310.

10 Jansen-Winkeln (1995) 85-115; Goldwasser (1999) 311-328; Nagai (2006) 223-232.

11 Goldwasser (1999) $316 \mathrm{f}$. 


\section{2 Übersicht über die Zeit von Amenophis III. bis Ramses II.}

Im Folgenden wird eine historisch-chronologische Gesamtübersicht über die Zeit vom Ende der 17. Dynastie bis einschließlich Ramses II. (19. Dyn.) gegeben, wobei die Zeit bis Amenophis III. nur sehr knapp dargestellt wird. Im Anschluss werden die Priester-, die Beamtenschaft sowie der Militärstand und ihre Rolle in der Politik besprochen.

\subsection{Historisch-chronologischer Überblick}

Politisch und religiös gesehen sind drei Hauptphasen zu unterscheiden:

1. Die erste Phase zeichnet sich durch vermehrte militärische Auseinandersetzungen sowohl in Vorderasien als auch in Nubien aus. Diese Phase entsteht unter den Königen der 17. Dynastie, denen es gelingt, die Hyksos aus Ägypten $\mathrm{zu}$ vertreiben und über das ganze Land $\mathrm{zu}$ herrschen, und endet unter Thutmosis IV. (ca. 1397-1388 v. Chr.) mit einem Friedensschluss mit dem Mitannireich. ${ }^{12}$ Daher gilt Thutmosis IV. als der König, unter dem sich der Wechsel von der militärischen zur diplomatischen Ebene vollzogen hat. ${ }^{13}$ Von diesem Zeitpunkt an zeigt sich ebenso eine Hinwendung von der Außen- zur Innenpolitik. In dieser Phase ist Amun Reichsgott.

2. Nach Thutmosis' IV. kommt Amenophis III. auf den Thron. Amenophis III. ernennt den „Kronprinzen“ (jr.j-p.t) Thutmosis zum „Größten der Leiter der Handwerker = Hohepriester von Ptah“ (wr hrrp.w-hmm.t) und zum „Vorsteher der Propheten von Ober- und Unterägypten“ (jm.j-rз ḥm.w-ntr m Šm .w Mḥ.w). ${ }^{14}$ Nach dem frühzeitigen Tod Thutmosis' wird sein Bruder Amenophis zum „Kronprinzen“ und kommt als Amenophis IV./Echnaton (ca. 1351-1334 v. Chr.) an die Macht. Seine ersten Regierungsjahre verbringt Amenophis IV. in Theben, wo er von Beginn an den Sonnengott Aton (Jtn) stärker betont und eine Abwendung vom Reichsgott Amun zeigt. Dies bezeugen sowohl die Namen seiner Töchter Meritaton, Maketaton und Anchesenpaaton als auch seine Bauten für den Gott Re-Harachte-Aton ( $R^{\prime}-H r$-3h.tj-Jtn).

12 Helck (1971) 163f., 168.

13 Gundlach (2004) $129 \mathrm{f}$.

14 Badawi (1948) $67 \mathrm{f}$. 
Amenophis IV. unternimmt viele Reformen. Im ersten Regierungsjahr wandelt sich der Kunststil, im dritten die Architektur radikal. Ab seinem vierten Jahr plant Amenophis IV. einen Umzug nach Tell el-Amarna. Etwa im fünften Regierungsjahr ändert er seinen Eigennamen in Echnaton (3h-n-Jtn) und ersetzt in seiner Titulatur Theben und Amun durch Achetaton (3h.t-Jtn) (Tell el-Amarna) und Aton. Im neunten Jahr beginnt Echnaton die Namen und Darstellungen des Gottes Amun und die Wörter „Gott“ (ntrr) und „Götter“ (ntrr.w) zu tilgen. Die Reform umfasst auch die Gräber und ihr Bildprogramm, den Glauben und die Jenseitsvorstellungen. ${ }^{15}$ Außenpolitisch herrscht zwar Frieden, Ägypten verliert unter Echnaton aber die Vorherrschaft in Vorderasien. ${ }^{16}$ Innenpolitisch entsteht ein Konflikt zwischen dem Königshaus mit seinen privilegierten arbeitslos gewordenen Militärbeamten einerseits und den mächtigen AmunPriestern von Theben andererseits.

3. Nach dem Tod Echnatons beginnt die dritte Phase, in der politisch und religiös ein Gegenzug und eine Rückkehr zum Alten festzustellen ist. In dieser Phase kommen hauptsächlich Pharaonen mit militärischer Laufbahn an die Macht.

Semenchkare (ca. 1337-1333 v. Chr.) regiert drei Jahre in Tell el-Amarna und Tutanchaton (ca. 1333-1332 v. Chr.) ein Jahr. ${ }^{17}$ Im zweiten Regierungsjahr ändert Tutanchaton seinen Namen in Tutanchamun (ca. 1332-1323 v. Chr.) und verlegt seine Residenz höchstwahrscheinlich nach Memphis. ${ }^{18}$ Es beginnt eine Phase der Restauration, in der $\mathrm{u}$. a. der Amun-Kult wiederhergestellt wird.

Nach dem plötzlichen Tod Tutanchamuns kommt Eje (ca. 1323-1319 v. Chr.) an die Macht. Außenpolitisch dürfte die Lage zunächst noch unverändert geblieben sein. ${ }^{19}$ Haremhab (ca. 1319-1292 v. Chr.) folgt Eje auf den Thron. Zu seiner Zeit werden der Name und die Darstellungen Echnatons beseitigt und dessen Bauten vernachlässigt und abgetragen. ${ }^{20}$ Außenpolitisch verschlechtert sich die Lage in Vorderasien, vor allem wegen der wachsenden Macht des Hethiterreiches, und die militärische Option wird als die einzige Lösung zum Erhalt der Vorherrschaft Ägyptens gesehen. ${ }^{21}$

Mit dem Tod Haremhabs ist die 18. Dynastie zu Ende. Ihm folgen Ramses I. (ca. 1292-1290 v. Chr.) und sein Sohn Sethos I. (ca. 1290-1279/78 v. Chr.) auf den

15 Baines (1998) $271 \mathrm{f}$.; Silverman (2006) 20-22, 34 f. und $39 \mathrm{f}$.

16 Ladynin \& Nemirovski (2010) 150-152.

17 Krauss (1997) $226 \mathrm{f}$.

18 Franke (2002) 13.

19 von Beckerath (1975) Sp. 1211.

20 Baines (1998) $272 \mathrm{f}$.

21 von Beckerath (1977) Sp. 963. 
Thron. Sethos I. unternimmt Feldzüge nach Palästina und Syrien. Es kommt zur Konfrontation mit dem Hethiterreich. ${ }^{22}$ Nach dem Tod Sethos' I. besteigt Ramses II. den Thron. Genauso wie sein Vater unternimmt er Feldzüge nach Vorderasien. Feldzüge nach Nubien und Libyen lassen sich ebenso belegen. Im 21. Regierungsjahr kommt es jedoch zu dem berühmten Friedensvertrag mit Hattusili III., der die Beziehungen zwischen Ägypten und dem Hethiterreich festlegt.

\subsection{Priester, Zivil- und Militärbeamte}

Die Umwandlungen der Amarnazeit werden auf „schlimme Dinge“ zurückgeführt, die in dem älteren Grenzstelentext [K, M, X 41f.]) von Tell el-Amarna Erwähnung finden und die Thutmosis IV., Amenophis III. und Amenophis IV. „hörten“:23

(1) jr [bn jrj.tw qrs=w jm=f] jw [bj]n st $r$ n3 $s \underline{d} m=j$ m h.3.t-sp 4 j[w bjn s]t $r$ [n3] $s \underset{d}{d m=j} m$ [h3.t-sp ...] jw bjn st $r$ n3 $s \underline{d} m[=j m$ h.3.t-sp 1] [jw bjn st $r$ n3 $s \underline{d m} \mathrm{Nb}$ $\left.M 3^{\circ} . t-\right] R^{\circ} j w$ bj[n] s[t r] n3 sdim Mn-Hpr[.w]-R 24

Wenn [man sie nicht in ihm (Achetaton) begraben wird], so ist das [schlim]mer, als was ich im Jahr 4 hörte, so [ist d] as [schlimm]er, als [was ]ich im [Jahr x] hörte, so ist das schlimmer, als was [ich im Jahr 1] hörte, [so ist das schlimmer, als was $\left.\mathrm{Nb}-\mathrm{M3}^{\circ} . t-\right] R^{*}$ (Amenophis III.) [hörte], so ist d[as] schlim[mer], als was Mn-Hpr[.w]-R (Thutmosis IV.) hörte.

Glaubt man diesem Text und sucht nach den Gründen, die diese Könige „schlimme Dinge hören“ lassen hätten, so ist nach dem Friedensvertrag Thutmosis’ IV. mit dem Mitannireich Folgendes festzustellen:

Bereits unter Thutmosis III. (ca. 1479-1425 v. Chr.) und Hatschepsut (ca. 1479/1473-1458/57 v. Chr.) lassen sich Militärbeamte erkennen, die in wichtige Hofämter in der Umgebung des Königs eingesetzt werden. ${ }^{25}$ Der Ämterhäufung und Machtkonzentration in der Zeit des Nachfolgers Amenophis' II. wird durch Thutmosis IV. und Amenophis III. entgegengewirkt. Verwaltungsämter, die zuvor nur den Priestern, den Zivilbeamten und ihrem Nachwuchs vorbehalten waren, werden nun auch von Militärbeamten bekleidet. Ein gutes Beispiel da-

22 Schneider (1994) 271.

23 Kees (1953) 79.

24 Helck (1958) 1975:9-13.

25 Helck (1964) $41 \mathrm{f} . ;$ Bryan (2006) 70 und $93 \mathrm{f}$. 
für ist der „Rekrutenschreiber“ (sḩsw-nfr.w) Amenophis, Sohn des Hapu, der unter Amenophis III. zu einem der wichtigsten Männer seiner Zeit wird. ${ }^{26}$

In der zweiten Hälfte der 18. Dynastie entfernen die Könige wichtige Ämter von Theben nach Memphis, wie z.B. dasjenige des „Obervermögensverwalters“ ${ }^{27}$ und des „Vorstehers der Propheten von Ober- und Unterägypten“. Dies wird als Absicht dieser Könige interpretiert, die gewaltige Macht der Hohepriester des Gottes Amun von Theben einzuschränken und ein Gegengewicht in Memphis zu schaffen. ${ }^{28}$ Das Amt des „Vorstehers der Propheten von Oberund Unterägypten“ ist in der 18. Dynastie bis Thutmosis IV. den „Hohepriestern von Amun“ vorbehalten, zwischen der Zeit Thutmosis’ IV. und Amenophis’ IV./ Echnatons wird dieses Amt nur einmal von dem „Hohepriester von Amun“ und „Wesir“ Ptahmose bekleidet, dessen Name jedoch seine Herkunft aus dem Norden andeutet. ${ }^{29}$ Ansonsten haben es Beamte bzw. „Hohepriester von Ptah“ inne. Erst am Ende der 19. Dynastie kehrt dieses Amt wieder nach Theben zurück. ${ }^{30}$ Kees sieht das Phänomen der Entfernung von Ämtern von Theben nach Memphis als das erste, das den König „schlimme Dinge hören“ lässt. ${ }^{31}$

Der Sonnenkult scheint unter Thutmosis IV. stärker betont worden zu sein. Während Amenophis II. seine Legitimation auf Amun aufbaut, stützt sich Thutmosis' IV. auf den Gott Harmachis (Hr-m-3h.t). ${ }^{32}$ Amun wird als göttlicher Vater Amenophis' II. angegeben, der göttliche Vater Thutmosis' IV. ist dagegen Harmachis-Chepre-Re-Atum (Hr-m-3h.t-Hpr.j-R'-Jtm). ${ }^{33}$ An die Tempel des Gottes Amun sind keine Stiftungen Thutmosis' IV. aus den Tributen belegt, im Gegensatz dazu lässt sich die Übergabe von Landbesitz an Harmachis in Gisa nachweisen. ${ }^{34}$ Von dieser Zeit an erlangt Aton, dessen Name bis zu diesem Zeitpunkt nur die Sonnenscheibe bezeichnet, allmählich eine größere Geltung. ${ }^{35}$ Die vielen Sonnenhymnen aus der 18. Dynastie, auch wenn viele davon AmunRe gewidmet sind, bekräftigen diese steigende Bedeutung des Gottes Aton. ${ }^{36}$ Der solare Kult ist bis Amenophis III. ein Geheimnis, das nur dem König zu-

26 Eichler (2000) 228-231.

27 Helck (1964) $49 \mathrm{f}$.

28 Badawi (1948) $67 \mathrm{f}$.

29 Aling (1984) 219.

30 Anthes (1931) 8.

31 Kees (1953) 81.

32 Klug (2002) 303.

33 Klug (2002) 234; Helck (1955) 1276:13; Helck (1957) 1542:17.

34 Eichler (2000) 227.

35 Gundlach (2004) 123; Dodson (2009) 2.

36 Baines (1998) 277. 
gänglich war. Amenophis III. und Amenophis IV./Echnaton bringen diesen Kult an die Öffentlichkeit. ${ }^{37}$ Der Bestandteil des Thronnamens Echnatons „Einziger des Re“ $\left(W^{*}-n-R^{\prime}\right)$ soll darauf hinweisen, dass er die Kenntnis des Gottes Aton auf sich alleine beschränken will. Daraus kann geschlossen werden, dass er die religiöse und politische Macht einzig für sich beanspruchen und die Entstehung einer mächtigen Elite oder Priesterschaft des neuen Gottes vermeiden will. $^{38}$

Etliche überkommene Formen werden abgelehnt. Thutmosis IV., Amenophis III. und Amenophis IV./Echnaton heiraten bürgerliche Frauen, nämlich Mutemwia, Teje und Nefertiti. Die königlichen Gemahlinnen Teje und Nefertiti werden in der Rundplastik z. B. im gleichen Maßstab wie Amenophis III. und Amenophis IV./Echnaton dargestellt. Die königlichen Kinder werden besonders in der Rundplastik und in der Malerei hervorgehoben. ${ }^{39}$

Ein weiterer Punkt ist die Politik der Beamtenrekrutierung. Echnaton stützt sich bei seinen Reformen auf Leute bescheidener Herkunft, vor allem auf Militärbeamte wie z.B. Maja, Eje, Pareemhab, Paatonemhab (= Haremhab) und den „Wesir“ Nacht(paaton). ${ }^{40}$ Von der alten Beamtenschaft seines Vaters lässt sich nur Parennefer identifizieren. ${ }^{41}$ Dass die neuen königlichen Beamten aus einem ganz anderen Milieu stammen, lässt sich aus den Aussagen dieser Personen entnehmen, ${ }^{42}$ die in der Literatur meistens als Bescheidenheit interpretiert werden. In solch hohem Maße und solcher Art lässt sich diese „Bescheidenheit" jedoch in keinen anderen Texten finden..$^{43}$ Die neuen Gefolgsleute beschreiben sich z. B. als „Arme; Bürger; Waise“ (nmh.w), die der König „schafft; zu etwas werden lässt; vornehm werden lässt“ $(q d)$ oder als „Nachwuchs; Rekruten; Generation“ (d 3 3m.w), den/die er „aufzieht“ (shpr). ${ }^{44}$ Ein anderes Indiz für die neue Politik der Beamtenrekrutierung ist die sog. Restaurationsstele Tutanchamuns, in der der Kindkönig Tutanchamun explizit erwähnt, dass er Beamten edler Herkunft, im Gegensatz zu Echnaton, wieder eingesetzt hat, wie im folgenden Zitat:

37 Baines (1998) $286 \mathrm{f}$.

38 Baines (1998) 288; Silverman u. a. (2006) 31.

39 Baines (1998) 292-298; Silverman u. a. (2006) 17-19.

40 Wilson (1951) 207; Kadry (1982) 79; Silverman (2006) 23.

41 Kees (1953) 84-88; Pflüger (1994) 124-126.

42 Kees (1953) 85; Pflüger (1994) $125 \mathrm{f}$.

43 Pflüger (1994) 125.

44 Pflüger (1994) 126. 
(2) bsj.n=f [ $w^{i} b . w^{]} h m . w$-ntr $m$ ms.w sr.w n.w njw.t=sn $m$ s3 $s$ rh $r h \underline{h} r n=f^{45}$

Er (Tutanchamun) führte ${ }^{[W a b-P r i e s t e r}{ }^{]}$und Propheten von den Kindern der hohen Beamten ihrer Stadt ein, als Sohn eines Mannes edler Herkunft, dessen Name bekannt ist.

Folgt man dem Text buchstäblich, kann man daraus die Schlussfolgerung ziehen, dass Echnaton die Amun-Priesterschaft entlassen und die Beamtenschaft seines Vaters durch Emporkömmlinge (Homines novi) ersetzt hat, die niederer Herkunft waren. ${ }^{46}$

Die Reformen der Amarnazeit deuten auf einen grundsätzlichen politischen Konflikt zwischen dem Königshaus und seinen begünstigten Militärbeamten einerseits und der Amun-Priesterschaft andererseits hin. Als Folge dieses Konflikts ist eventuell die Betonung des Sonnenkultes $\mathrm{zu}$ interpretieren, die gleichzeitig mit dem Beginn des „schlimme Dinge hören“ unter Thutmosis IV. aufzutauchen scheint. Unter Amenophis IV./Echnaton erreicht dieser Konflikt seinen Höhepunkt, als Echnaton eine riesige Tempelanlage für Aton in Karnak erbauen lässt, deren Steinbruchexpedition er den „Hohepriester von Amun“ May zu leiten beauftragt. Für den Reichsgott Amun findet sich unter Echnatons Herrschaft dagegen nichts Erwähnenswertes. In Tell el-Amarna stützt sich Echnaton ausschließlich auf eine neue Schicht von Leuten, die zum größten Teil aus Militärbeamten besteht. Wahrscheinlich aus diesem Grund finden sich viele Darstellungen von Soldaten sowohl auf Blöcken des AtonTempels in Karnak als auch in Gräbern von Tell el-Amarna. ${ }^{47}$ Von der alten Priester- und Beamtenschaft, mit Ausnahme von Parennefer, sind keine Spuren mehr greifbar. Darstellungen und Namen der thebanischen Triade und die Wörter Gott (ntrr) und Götter (ntr.w) scheinen nicht aus religiösem Hass gegen den Gott Amun bzw. andere Götter ausgetilgt worden zu sein, sondern höchstwahrscheinlich um ihre Ansprüche auf Stiftungen zu untergraben. ${ }^{48}$

Dieser Erklärungsansatz lässt sowohl die politische als auch die religiöse Interpretation der Krise gelten, wobei der politische Konflikt um die Macht als der Grund und die religiöse Reform als eine Konsequenz zu betrachten sind.

45 Helck (1958) 2029:9f.

46 S. hierzu Silverman (2006) 22, 34.

47 Shirley (2013) $596 \mathrm{f}$.

48 Kessler (2012) 163-171. 


\section{Sprache}

Das Ägyptische ist eine der ältestbezeugten und am längsten kontinuierlich in schriftlicher Überlieferung belegten Sprachen überhaupt. Es hat eine Geschichte, die sich von ca. 3320 v. Chr. bis ins 10. Jh. n. Chr. belegen lässt, als es vom Arabischen als Gebrauchssprache abgelöst wurde. ${ }^{49}$

\subsection{Historische Sprachentwicklung}

Die Grammatiken der ägyptischen Sprache sind vorwiegend synchrone Grammatiken, die die jeweilige Sprachstufe als ein einheitliches Sprachsystem darstellen. Ihre Beschreibungen beschränken sich jedoch auf bestimmte Schriftarten, Textsorten und Zeitabschnitte: Altägyptisch, Mittelägyptisch, Neuägyptisch, Demotisch und Koptisch.

Das Altägyptische wird in ein frühes und ein „eigentliches“ Altägyptisch unterteilt. Das frühe Altägyptisch bzw. Frühägyptisch ist in sehr kurzen Hieroglypheninschriften in der 0.-3. Dynastie (ca. 3320-2707/2657 v. Chr.) überliefert. ${ }^{50}$ Das „eigentliche“ Altägyptisch ist bis zum späten Alten Reich (ca. 26822145 v. Chr.) vor allem in den Pyramidentexten und Autobiographien anzutreffen. ${ }^{51}$

Mittelägyptisch ist vom späten Alten Reich bis zum Ende der Hieroglyphenschrift überliefert. ${ }^{52}$ Dabei werden klassisches Mittelägyptisch, Spätmittelägyptisch und Neo-Mittelägyptisch unterschieden. Klassisches Mittelägyptisch umfasst hieroglyphische und hieratische Texte aller Gattungen vom Ende des Alten Reiches bis in die 18. Dynastie. ${ }^{53}$ Im Unterschied zum klassischen Mittelägyptisch macht Spätmittelägyptisch ab und zu von sog. Neuägyptizismen Gebrauch. Es wird grundsätzlich in den theologischen und teilweise in den Dekorumstexten, aber auch in den Alltags- und literarischen Texten der 2. Zwischenzeit und des Neuen Reiches verwendet. ${ }^{54}$ Als Neo-Mittelägyptisch wird Mittelägyptisch bezeichnet, das in den Tempelinschriften und religiösen Texten von der 19. Dynastie bis zum Absterben der Hieroglyphenschrift in Gebrauch ist. ${ }^{55}$

49 Junge (1984) Sp. 1177.

50 Kahl (1994) 5-10; Kahl (2002) I, V f.

51 Junge (1984) Sp. $1189 \mathrm{f}$.

52 Allen (2010) 646.

53 Loprieno (1995) 5 f.; Junge (1984) Sp. 1190.

54 Junge (1984) Sp. 1190.

55 Allen (2010) 646; Junge (1984) Tbl. 2 nach Sp. 1184. 
Ab dem Neuen Reich ist neben Spätmittelägyptisch das Medio-Neuägyptische anzutreffen. Es besteht nahezu vollständig aus neuägyptischer Satzstruktur und vielen mittelägyptischen Formen. Es wird zuerst nur in Alltagstexten, ab der Amarnazeit auch in den literarischen und Dekorumstexten und in der 19.-20. Dynastie nur teilweise in den Dekorumstexten verwendet. Das Neuägyptische kommt von der späten 19. bis zur frühen 21. Dynastie in den Alltags-, literarischen und offiziellen Texten vor. ${ }^{56}$ Neben Neo-Mittelägyptisch in den theologischen und staatlichen Registern ist ab etwa 650 v. Chr. Demotisch zuerst in den Alltags- und literarischen Texten und ab der Römerzeit bis ins 5. Jh. n. Chr. in allen Sprachregistern zu finden. ${ }^{57}$ Im Verlauf des 4. Jhs. n. Chr. werden das Neo-Mittelägyptische und das Demotische durch das Koptische abgelöst. ${ }^{58}$

Diachron betrachtet, entwickeln sich die gesprochene und die geschriebene Sprache anders. Die Schriftsprache hat ihre Regeln, die eingehalten und von Neuerungen in der Umgangssprache reingehalten werden. Die Entwicklung der gesprochenen Sprache schreitet dagegen vergleichsweise ungezwungen vorwärts, ${ }^{59}$ da in ihr andere Inhalte ausgesprochen werden und ganz andere und vielschichtigere soziale Reglements gelten als in der Schriftsprache. Wenn diese Inhalte schriftlich formuliert werden, kommt eine andere Sprachnorm zum Einsatz, zu der die Schreiber wechseln können. ${ }^{60}$ Wenn die Kluft zwischen der Umgangssprache und den Normen der Schriftsprache besonders groß ist, dann können sprachliche Fehler versehentlich auftreten, die wertvolle Anhaltspunkte für die Umgangssprache der Schreiber bieten können. ${ }^{61}$ Die gesprochene Sprache wird nach einer gewissen Zeit zu einer geschriebenen Sprache. Ein sehr wichtiger Faktor dabei sind geschichtliche und religiöse Umwälzungen, die auch eine Umwälzung schriftsprachlicher Normen mit sich bringen können. Wenn dies geschieht, kann die Umgangssprache zur Quelle neuer schriftsprachlicher Normen werden. Danach beginnt derselbe Prozess wieder von vorne. $^{62}$

56 Junge (1984) Tbl. 2 nach Sp. 1184. Jansen-Winkeln verwendet für alle Texte des Mittelägyptischen als „zweiter Schriftsprache“ von der 19. Dynastie bis zum Ende der Pharaonenzeit die Bezeichnung Spätmittelägyptisch, s. Jansen-Winkeln (1994) 1-3. Bei seiner Behandlung des Schriftsystems und der Sprache der Tempelinschriften der ptolemäisch-römischen Zeit spricht Kurth vom Ptolemäischen als „künstlichem Idiom“, Kurth (2007) 3-8.

57 Junge (1984) Tbl. 2 nach Sp. 1184; Loprieno (1995) 7.

58 Krause (1980) Sp. 731.

59 Sethe (1925) $302 \mathrm{f}$.

60 Junge (2008) 19.

61 Kroeber (1970) XVII.

62 Sethe (1925) $315 \mathrm{f}$. 
Typologisch gesehen, wird zwischen dem sog. älteren Ägyptisch und dem jüngeren Ägyptisch unterschieden. Mit dem älteren Ägyptisch werden die synthetischen Sprachstufen Altägyptisch und Mittelägyptisch zusammengefasst. Das jüngere Ägyptisch umfasst die analytischen Sprachstufen Neuägyptisch, Demotisch und Koptisch. ${ }^{63}$ Im Folgenden wird der Übergang zwischen den beiden Sprachgruppen anhand von charakteristischen Sprachphänomenen dargestellt.

\section{2 Übergang vom Mittel- zum Neuägyptischen}

Zwei Wandlungsprozesse beeinträchtigen das ältere, überwiegend synthetische Sprachsystem und führen zur Entstehung eines neuen, meist analytischen Systems:

1. Phonologische Änderungen bewirken das Verschwinden von altägyptischen und mittelägyptischen charakteristischen Morphemen wie z. B. dem Infix.$n$ - in den $s d m . n=f-$ Formen $^{64}$ und der Geminierung der III-inf.Verben, ${ }^{65}$ und führen zur Verallgemeinerung des Gebrauchs des Hilfsverbs jrj $^{66}$ und Neugestaltung des temporalen und modalen Mechanismus;

2. die Rolle der Partikel jw ändert sich von einer hauptsatzeinleitenden Partikel zu sowohl Umstandskonverter als auch Koordinator in der sog. Narrativen Sequenz. ${ }^{67}$

\subsubsection{Entwicklung ausgewählter Sprachphänomene}

Im Folgenden wird die historische Entwicklung ausgewählter Sprachphänomene abgehandelt, die alle Sprachebenen repräsentieren, häufig vorkommen und jeweils mit einem genau identifizierbaren und leicht abgrenzbaren Gegenstück in der anderen Phase des Ägyptischen verknüpft werden können. Mit diesem Auswahlprinzip werden saubere Ergebnisse erzielt, die für statistische Analysen geeignet sein können und auf die man sich bei der Behandlung der Fragestellung stützen kann.

63 Junge (1984) Sp. 1177-1187.

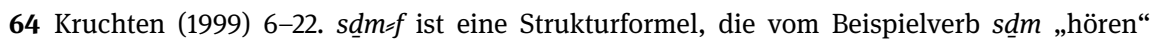
und Suffixpronomen $=f$,er" genommen ist und mit deren Hilfe die ägyptischen Zeitformen der Suffixkonjugation dargestellt werden.

65 Kruchten (1999) 22-24.

66 Kruchten (1999) 24-47.

67 Kruchten (1999) 52-81. 


\section{Possessivsuffix und Possessivartikel}

Im synthetischen Ägyptisch drücken die sog. Possessivsuffixe das Besitzverhältnis aus, wie z. B.: $p r=s$ „,ihr Haus“, hlm.t=f „seine Frau“, hrrd.w=n „unsere Kinder“. Da determinieren die Possessivsuffixe $=s$, $=f$ und $=n$ ihre Bezugswörter $p r, h m . t$ und $h r d . w$. Das analytische Pendant besteht aus den neuägyptischen Demonstrativa $p 3 j$, $t 3 j$ und $n 3 j$ und dem Suffixpronomen, das auf das Besitzverhältnis hinweist. Der Possessivartikel kann alleinstehend auftreten ${ }^{68}$ oder artikelhaft vor einem Nomen verwendet werden. Nur die zweite Variante wird hier berücksichtigt. Die oben angeführten Beispiele werden im Neuägyptischen wie folgt ausgedrückt: $p 3 j=s p r, t 3 j=f$ hm.t und $n 3 j=n$ hrd.w.

Schon in der 6. Dynastie lässt sich ein Beleg für die Possessivartikel im Grab von Nianchpepi in Saqqara finden:

(3) (w)dj(-j) p3w=f hrw nd

Ich setzte seinen Tag der Haft bleibend ewiglich zur Stätte „Herabgestiegen-befriedigt-verklärt“ in seiner Falle.

Im Mittleren Reich lassen sich andere Belege identifizieren, die unregelmäßig neben den Possessivsuffixen auftauchen. ${ }^{70}$ Erst im Laufe des Neuen Reiches setzen sich die Possessivartikel durch und können regelmäßig erscheinen. Einige Substantive wie z. B. Körperteile, Ausdrücke für Zeit und Verwandtschaftsbezeichnungen kommen auch noch mit den alten Possessivsuffixen, allerdings auch selten mit den Possessivartikeln, vor: $j b=f$,,sein Herz“, $r k=n$, unsere Zeit“, $j t=s$,ihr Vater“, $n j t=j$ p 3 Jtn $p 3 j=j$ jt „gegenüber meinem Vater (jt=j), dem Aton, meinem Vater $\left(p_{3 j} j j j t\right){ }^{*} .^{71}$

\section{Demonstrativpronomina $p n, t n, n n$ und $p_{3} j, t_{3 j}, n_{3 j}$}

Im älteren Ägyptisch werden vier Reihen von Demonstrativa unterschieden: $p w, t w$ und $n w$,diese(r/s)“; $p n$ (älterer Pl. jpn), tn (älterer Pl. jptn) und $n n$ „diese(r/s)“; $p f$ (älterer Pl. jpf), $t f$ (älterer Pl. jptf) $)^{72}$ und $n f$, ,jene(r/s)“ und $p 3$, $t_{3}$ und $n 3$,diese $(\mathrm{r} / \mathrm{s})$ “. Die Pronomina $p w, t w, p n$, $t n$ und $p f$, $t f$ stehen in der Regel nach einem Nomen, ${ }^{73} p_{3}$ und $t_{3}$ befinden sich dagegen vor einem Bezugswort. Die Formen $n w, n n, n f$ und $n 3$ treten entweder vor einem Substantiv oder

68 Erman (1933) §179.

69 Hassan (1975) 22, Taf. XIX.A.

70 s. Brose (2014) §§ $52 \mathrm{f}$.

71 Murnane \& Van Siclen (1993) 95:B16.

72 Für die älteren Pluralformen mit jp- s. Edel (1955/1964) §§ 182 und 184; Gardiner (1957) § 110.

73 Edel (1955/1964) §§ 185f., 188-193. 
selbstständig als Nomen auf. ${ }^{74}$ Das $n w$ kann mit einem Suffixpronomen versehen werden und den Besitz anzeigen. ${ }^{75}$

Die Auswahl einer der Reihen hängt von der Sprachnorm ab. In den theologischen Texten wird die $p w$-Reihe favorisiert und die $p n$-Reihe toleriert. In den literarischen Texten wird die $p n$-Reihe favorisiert und die $p$-Reihe toleriert. In der niedrig angesetzten Sprachnorm wird die $p 3$-Reihe am häufigsten eingesetzt. Diese zunächst tolerierten Reihen werden durch die Ausbreitung im Sprachgebrauch in andere Sprachnormen übernommen und verdrängen nach und nach die anderen Reihen. ${ }^{76}$ Die Reihe $p 3$, $t 3$ und $n 3$ entwickelt sich im Laufe der Zeit zu Artikeln (18. Dyn.). ${ }^{77}$

Im Neuägyptischen ist eine neue Reihe von Demonstrativa zu finden, nämlich $p_{3 j}, t_{3 j}$ und $n_{3 j}$ bzw. $n 3 w$, die etymologisch auf die älteren $p_{3}, t_{3}$ und $n_{3}$ zurückgeführt wird. Diese werden vor ein Bezugswort gestellt, können aber selbstständig vorkommen. ${ }^{78}$ Neben diesen Standardformen gibt es noch die Nebenform $p 3 w$, die absolut als ein Nomen, aber auch vor einem Relativsatz oder Substantiv gebraucht wird. ${ }^{79}$

Der erste Beleg für die neuägyptischen Demonstrativa stammt aus dem Mittleren Reich:

(4) $s w \underline{d} 3-j b[p w] n n b{ }^{~} n h-w \underline{d} 3-s(n b)$ hr pзj 'm-jb n nb 'nh-wdz-snb (P. UC 32203: Recto 2f.)

Eine Mitteilung [ist es] für den Herrn, er lebe, sei heil und gesund, über dieses Versäumnis des Herrn, er lebe, sei heil und gesund.

Danach bis in der Mitte der 18. Dynastie sind keine anderen Fälle zu finden. In der Zeit Hatschepsuts taucht $p 3$ j in bzw. als Eigennamen auf (P. BM 10102:2 und Verso 7). Aus der Zeit Thutmosis' III. und Amenophis' II. sind zwei Beispiele bekannt. ${ }^{80}$ Erst in der Amarnazeit kommen $p 3 j$ und t3j zur Entfaltung, sogar in den Dekorumstexten:

(5) bn wsf.tw p3j ' nh jrj.w n jt=j p3 Jtn p3j=j jt ${ }^{81}$

Man wird diesen Eid nicht brechen, der gegenüber meinem Vater, Aton, meinem Vater, geschworen wurde.

74 Edel (1955/1964) §§ 196-199, 201.

75 Edel (1955/1964) § 200.

76 Junge (1985) 23.

77 Edel (1955/1964) § 195; Kroeber (1970) 13-28.

78 Erman (1933) §§ $123 \mathrm{f}$.

79 Erman (1933) § 120.

80 Kroeber (1970) 40.

81 Murnane \& Van Siclen (1993) 94 f.:B15f. 
Die ersten Belege für nзj stammen aus der Zeit Ramses’ II., wie aus P. Leiden I.368:11:

(6) jn jw.tw $r$ jnj(.t)=w jw=sn $r$-h. $3 . t$ nзj $r m \underline{.} . w^{82}$

Soll man sie bringen, indem sie vor diesen Leuten sind?

Die Demonstrativa pn und tn können in festen Wortverbindungen wie hrw pn „dieser Tag“, sḩзw pn,,dieser Schreiber“, in Briefen sḩ3 pn $n$ NN „dieses Schreiben des NN“, ntr pn „dieser Gott“, dmj\{.t\} pn „diese Stadt“, s.t tn „dieser Ort“ in in reinem Neuägyptisch verfassten Texten erscheinen. ${ }^{83}$ Der Plural $n n$ kann sowohl selbstständig in festen Redensarten wie hrr-s3 nn „danach“ als auch vor einem Substantiv wie $n n$ wr.w „diese Großen“ auftreten. ${ }^{84}$

Versucht man den sprachlichen Wandel der Demonstrativa in eine Reihenfolge $\mathrm{zu}$ bringen, so kann man zuerst den Wechsel von den nachgestellten $\mathrm{zu}$ den vorangestellten Demonstrativa feststellen. Das geschah etwa in der zweiten Hälfte des Alten Reiches, wo die Demonstrativa $p_{3}, t_{3}$ und $n 3$ entstanden sind. Gleichzeitig mit einem Schwund der Endungen der Substantive, die das Genus und den Numerus ausdrückten, entwickelten sich $p 3, t 3$ und $n 3$ semantisch zu Artikeln: hm.t wird zu t3 hm(.t). Von diesem Zeitpunkt an waren die neuägyptischen Demonstrativa $p 3 j, t_{3 j}$ und $n 3 j$ völlig entwickelt. ${ }^{85}$

Unten sub 4 werden die Demonstrativa der älteren Reihe $p n$, $t n$ und $n n$ und die neuägyptischen $p 3 j, t_{3 j}$ und $n 3 j$ statistisch ausgewertet. Berücksichtigt werden ausschließlich diejenigen, die nach respektive vor einem Bezugswort erscheinen.

\section{Suffixpronomen der 3. P. Pl. =sn und $=w$}

Die Personalsuffixe =sn \筑, das neuägyptische Gegenstück werden sowohl an Konjugationsformen als Subjekt oder Objekt, als auch an Substantiven als Possessivsuffix, an neuägyptischen Demonstrativa als Possessivartikel, an Partikeln als Subjekt, an Präpositionen als Präpositionalobjekt und in dem unabhängigen Pronomen (j)nt=sn > $m n t=w$ verwendet. Im Laufe der ägyptischen Sprachentwicklung wird die klassische Form durch die neuägyptische abgelöst.

Das Suffix $=s n$, jedoch als $=s$ mit dem Pluraldeterminativ $\int_{0}^{0}, \infty$ und ohne das auslautende $n$, ist zuerst in Inschriften aus dem späten Mittleren Reich

82 Kitchen (1979) 894:11f.

83 Erman (1933) § 114.

84 Kitchen (1979) 242:11; Erman (1933) § 117.

85 Hintze (1947) 91; Kroeber (1970) 40. 
und der 2. Zwischenzeit aus der Gegend von Edfu bezeugt. ${ }^{86}$ Dass das $n$ im Verschwinden begriffen war, war nicht nur auf Edfu beschränkt, wie es anhand von den Stelen 97E und 287E aus Esna und anderen aus Abydos zu bestätigen ist. ${ }^{87}$ Hinter diesem Phänomen scheint ein phonetischer Wandel zu stecken. Das Suffix =sn könnte in dieser Gegend ab dieser Zeit nicht mehr als =sn, sondern nur als $=s$ ausgesprochen worden sein. ${ }^{88}$ Dieser Zustand führt wahrscheinlich zu Verwechslungen zwischen $=s n$ 3. P. Pl. und $=s$ 3. P. Sg. fem., was einige Belege ab der Mitte der 18. Dynastie bestätigen. ${ }^{89}$ Vor allem als Objekt oder

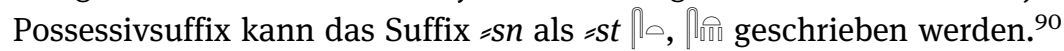

Das Neuägyptische kennt ein anderes Personalsuffix für die 3. P. Pl., nämlich $=w,{ }^{91}$ das alle Aufgaben des alten Suffixes $=s n$ übernimmt. Das Suffix $=s n$ bleibt jedoch in normhierarchisch höheren Textsorten noch lange in Gebrauch. ${ }^{92}$

Die ältesten Belege für das Suffix $=w$ sind sowohl im $s \underline{d} m=f$, das seinerseits das $s \underline{d m} . n=f$ ersetzt, als auch an die Partikel $j w$ angehängt anzutreffen. Das $s \underline{d} m=f$ taucht auf der Kamose-Stele (Zeile 18) aus der 17. Dynastie mit dem Suffix $=w$ auf. Zu Beginn der 18. Dynastie kommt das Suffix $=w$ am Verb und an der Partikel jw mehrmals vor. ${ }^{93}$ Ab der Zeit Echnatons wird dieses Suffix nicht nur durch das Determinativ des Plurals .w an, sondern durch das phonetische $w$ zusammen mit dem Determinativ des Plurals geschrieben und als Suffix an Substantive und Infinitive gehängt. ${ }^{94}$

In diesem Beitrag werden alle Vorkommensweisen beider Suffixe statistisch ausgewertet.

\section{Konjunktiv $h n^{\circ} n t f(t m) s \underline{d} m$ und $m t w=f(t m) s \underline{d} m$}

Der sog. Konjunktiv ist eine ägyptische Konstruktion, mit der die Funktion einer vorangehenden Verbalform weitergeführt wird und die dabei eine koordinierende Bedeutung „und“ hat. ${ }^{95}$

Die Form des Konjunktivs ändert sich seit der 1. Zwischenzeit in drei Etappen. Die erste Phase des Konjunktivs erstreckt sich von der 8. bis zur 18. Dynas-

86 Gunn (1929) 6; Kroeber (1970) $33 \mathrm{f}$.

87 Downes (1974) Abb. 35 und 45; Meltzer (1980) 34.

88 Kroeber (1970) 33.

89 Kroeber (1970) $34 \mathrm{f}$.

90 Erman (1933) §79.

91 Zur Herkunft dieses Suffixes =w, s. Edel (1959) 17-38; Kroeber (1970) $36 \mathrm{f}$.

92 Junge (2008) 53.

93 Kroeber (1970) $38 \mathrm{f}$.

94 Behnk (1924) 12.

95 Junge (2008) $248 \mathrm{f}$. 
tie. Seine Form besteht aus der Präposition ḥn „zusammen mit; und“, dem Infinitiv und einem fakultativen unabhängigen Pronomen bzw. jn Nomen als Agens: $h n^{\prime} s \underline{d} m$ ( $\left.n t f\right) / \underline{h} n^{\prime} s \underline{d} m$ (jn Nomen). Wenn das Subjekt des Konjunktivs in dieser Phase Erwähnung findet, dann stimmt es mit dem der vorangehenden Form überein. ${ }^{96}$

Von der Zeit Hatschepsuts an bis zur Zeit Ramses' II. existiert eine Form, die nichts anderes als eine neue Anordnung der Elemente des Konjunktivsatzes zu sein scheint ${ }^{97}$ und wie folgt aussieht: $h n^{\circ} n t f s \underline{d m} / h n^{\circ} n . t j$ Nomen $s \underline{d m} .{ }^{98}$ Das Agens der Konjunktivkonstruktion wird obligatorisch, allerdings mit wenigen Ausnahmen, wie z. B. wenn das Subjekt des vorangehenden Satzes .tw „man“ ist, ${ }^{99}$ oder wenn die Form ein Passiv ist. ${ }^{100}$ Außerdem kann das Agens sich von dem des vorangehenden Satzes unterscheiden. Damit ist der Subjektwechsel gemeint, der allmählich zunehmend in Gebrauch kommt.

Die dritte Phase ist aus einer Form zusammengesetzt, die eine Konjugationsbasis $m t w$, manchmal als $\triangle, \triangle m$-dj geschrieben, ein Suffixpronomen oder ein Nomen und einen Infinitiv als Bestandteile hat: $m t w=f s d m$ / $m t w$ Nomen $s \underline{d m} .^{101}$ Diese Phase erstreckt sich von der 2. Zwischenzeit ${ }^{102}$ bis hin zum Koptischen, die Mehrheit der Belege setzt jedoch erst ab der Amarnazeit ein.

Betrachtet man die Entwicklungsgeschichte des Konjunktivs, so kann man feststellen, dass sich das Agens immer wieder nach vorne vordrängt: $h n^{\circ} s \underline{d m}$ (ntf)/hn $s \underline{d} m$ (jn Nomen) > ḥn $n t f s \underline{d} m / h n^{\circ} n . t j$ Nomen $s \underline{d} m>m t w=f s \underline{d m} / m t w$ Nomen $s \underline{d m}$. In Analogie zu Konstruktionen wie $m j$ ntf nominales/adjektivisches Prädikat oder $\underline{d} r n . t t=k$ Pseudopartizip entsteht die zweite Form $h n^{\circ} n t f$ $s \underline{d} m / h n^{\circ} n . t j$ Nomen $s \underline{d m} .{ }^{103}$ Im Laufe der Entwicklung fällt die Präposition $h n^{*}$ aus, was an einem Beispiel bereits aus der Zeit Ramses' III. (ElephantineDekret, Zeile 7) festzustellen ist:

(7) htm.tjw rmt.w nb(.w) n ḥw.t-ntrr n.tj jw.tw $r$ thj.t $r=f$ ntf $\underline{d} d^{104}$

Jeder Siegler, jeder Mensch von dem Tempel, der sich darin einmischen wird und sagen wird (...).

96 Kroeber (1970) 152-161.

97 Mit Ausnahme der Partikel jn, die durch n.tj ersetzt wird.

98 Kroeber (1970) 162-169.

99 Haremhab-Dekret: Helck (1958) 2149:10-12.

100 Nauri-Felsstele: Kitchen (1975) 56:1.

101 Kroeber (1970) $152 \mathrm{f} ., 169 \mathrm{f}$.

102 P. Louvre E 32308:4-7. Im P. Louvre E 32308:4-7 sind fünf Fälle zu identifizieren, s. hierzu Koenig (2004) 292 und $322 \mathrm{f}$.

103 Gardiner (1928) 88 f.; Kroeber (1970) $144 \mathrm{f}$.

104 Kitchen (1983) 344:5 f. 
und $n t f$ wird zu $m t w=f$, obwohl das unabhängige Pronomen im Neuägyptischen als mntf auftritt. ${ }^{105}$ D.h. der Zusammenhang mit dem unabhängigen Personalpronomen geht verloren. Ein Brückenbeleg stammt aus dem P. Kairo CG 58053:Recto 7-9, Verso 1, wo anstelle des erwarteten unabhängigen Pronomens ein Suffixpronomen auftaucht:

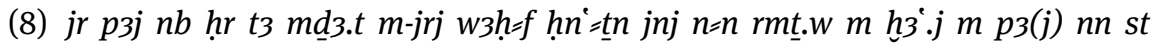

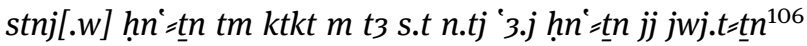

Was dies alles auf dem Schriftstück anbelangt, so lasst es nicht außer Acht, sondern bringt zu uns Leute von denen, die zurückgelassen wurden, ohne sie zu unterscheiden, und bewegt euch nicht von dem Platz hier, sondern macht euch sofort daran, zu kommen.

Ein besonderer Fall ist P. Northumberland 1:Recto 6-9, wo beide Formen der zweiten und dritten Phasen erscheinen:

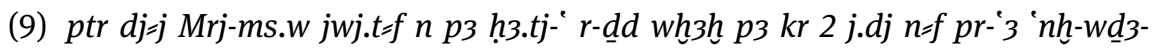
snb $m t w=k$ dj.t wh3h.tw=w $n=f m$ s.t $n b$ hn $n t k$ dj(.t) $h r=k n M r j-m s . w j w=f d j$ $m-d j=k^{107}$

Siehe, ich ließ den Merimose zum Bürgermeister gehen und sagen: Suche die zwei Ker-Schiffe, die der Pharao, er lebe, sei heil und gesund, ihm zugeteilt hatte, und veranlasse, dass man sie für ihn überall sucht. Und du bist es, der sich Merimose zuwendet, wenn er hier mit dir ist.

Der neuägyptische Konjunktiv $m t w=k$ dj.t (...) tritt in dem Zitat als gesprochene Sprache auf, während die ältere Form $h n^{*} n t k d j(. t)(. .$.$) im nicht zum Zitat gehö-$ renden Text erscheint. ${ }^{108}$ Im Haremhab-Dekret und dem Dekret von Nauri treten beide Formen des Konjunktivs auf, jedoch ohne Unterschied im Gebrauch.

Abschließend ist noch zu sagen, dass die verschiedenen Konjunktivfor-

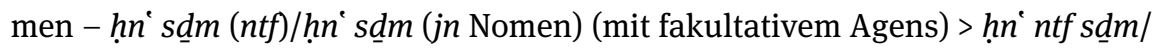
$h n^{\circ}$ n.tj Nomen $s \underline{d m}$ (mit obligatorischem Agens an zweiter Position) $>m t w=f$ $s \underline{d} m / m t w$ Nomen $s \underline{d m}$ (mit $m t w$ anstelle von $h n^{\circ}$ ) - im Prinzip in den klassisch mittelägyptischen Dekorums- und religiösen Texten nicht vorkommen. Ihr Gebrauch beschränkt sich anfangs auf mittelägyptische literarische und nichtliterarische Texte, später tauchen sie jedoch in anderen Textsorten auf.

105 Gardiner (1928) 94; Kroeber (1970) $143 \mathrm{f}$.

106 Kitchen (1975) 322:11-13.

107 Kitchen (1975) 239:8-10.

108 Kroeber (1970) $166 \mathrm{f}$. 


\section{Sätze mit Negationen $n, n n$ und $b w, b n$}

Die altägyptische Negation $n j$ weist verschiedene Schreibvarianten $\Omega$, $\Omega$, $\Omega, \ldots, \Omega \Omega$, auf. ${ }^{109}$ Aus dem altägyptischen $n j$ entstehen zwei mittelägyptische Partikeln, $n \_$und $n n \_$, die morphologisch und syntaktisch voneinander zu trennen sind. ${ }^{110}$ Während $n$ „nicht“ in negativen Verbalsätzen, wie z.B. $n s \underline{d} m=f, n s \underline{d} m . n=f$ und $n s \underline{d} m . t=f$, auftritt, kommt $n n$ „es ist nicht“, „es gibt nicht" als Prädikat vor allem im negativen Adverbialsatz, im Nicht-Existenzsatz, im prospektiven $n n s \underline{d} m=f$ und im nominalen $n n s \underline{d m} . n=f$ vor. ${ }^{111}$ Außerdem wird die Negation $n$ mit anderen Elementen kombiniert, wie $n$-sp „niemals“, $n$-js bzw. $n$... js ,nicht“. ${ }^{112}$

In normhierarchisch höheren Texten können schon ab der 17. Dynastie Verwechslungen zwischen $n$ und $n n$ festgestellt werden, die auf Unsicherheit in der Orthographie des klassischen Mittelägyptisch zurückzuführen sind. ${ }^{113}$ Ein Fall stammt aus der Zeit Amenophis' III., wo anstelle von nn Adverbialsatz nur $n$ geschrieben ist:

(10) $n(n)$ sw hr jt jt $m$ špss $m$ w' pw $n$ w'r s3-R ${ }^{\circ 114}$

Niemand ist für Vater des Vaters mehr der Heilige und der Allereinzige als der Sohn des Re.

Gleichzeitig mit der Zunahme der Verwechslungen zwischen $n$ und $n n$ gewinnen die neuägyptischen Pendants ${ }^{115} b w \sqrt{\Omega}$, Je und $b n \cong$ an Bedeutung, bis sie die älteren Verneinungen völlig ablösen. Der bis jetzt älteste Beleg der Negation $b w$ befindet sich auf einer Stele aus Achmim aus der Zeit Pepis II..116

(11) $\quad b(w) j j(j) h . t j m(-j)$ (Stele Achmim:3 f.)

Nichts kam von (mir).

In der 1. Zwischenzeit und im Mittleren Reich kommt die Negationspartikel $b w$ in Eigennamen in Naga el-Dêr und Abydos vor, etwa wie in $B(w)-k m . n(=j)$,Ich-

109 Edel (1955/1964) §§ 16, 1076.

110 Edel (1955/1964) § 1076; Gunn (1924) § 10, 88-92.

111 Gunn (1924) § 14, 127-130; Gardiner (1957) § 104.

112 Gardiner (1957) § 106.

113 Kroeber (1970) 66.

114 Helck (1957) 1674:13 f.

115 Zum Ursprung der neuägyptischen Verneinungspartikeln $b w$ und $b n$, s. Clère (1956) 2733; wie es von dem Phonem /n/ zu /b/ kommt, s. Davis (1973) 183-202.

116 Fischer (2006) 34-37; El-Hamrawi (2007) 43. 
habe-nicht-vollendet“, $B(w)$ rh=f „Er-weiß-nicht“. ${ }^{117}$ Eindeutige Belege - außer in den Eigennamen - sind ab der Zeit der Königin Hatschepsut zu finden. Im P. BM 10107:Recto 7 löst die Verneinungspartikel $b w$ im präteritalen $b w s \underline{d} m=f$ die ältere Negation $n$ der $n s \underline{d} m=f$-Form $a b:^{118}$

(12) $\quad r \underline{d} d$ mj k3 wpt=k ḥn =f bw wšb=f Mnw.j (P. BM 10107:Recto 7)

Um zu sagen: „Komm, so dass du mit ihm richten sollst!“ Aber er, Menui, antwortete nicht.

Das Verneinungswort $b n$ ist zum ersten Mal in den Annalen Thutmosis' III. belegt:

(13) js bn šm ssm.t m-s3 ssm.t rmt..w mj.tt ${ }^{119}$

Wird nicht Gespann hinter Gespann gehen, Leute ebenso?

In der Amarnazeit treten die Negation $b w$ und $b n$ häufiger als die mittelägyptischen $n$ und $n n$ auf, ${ }^{120}$ die im Laufe der Zeit aus den hierarchisch niedrigen Sprachnormen fast komplett durch die jüngeren verdrängt werden. In hierarchisch höheren Sprachregistern aber finden sie bis an das Ende der Pharaonenzeit noch Gebrauch.

Ausgehend von dieser Schlussfolgerung und bestätigt durch die Belege, kann gesagt werden, dass die Verneinungspartikel $b w$ bereits in der 1. Zwischenzeit entstanden ist und dass ihr Ursprung in der Gegend von Achmim, Naga el-Dêr und Abydos zu verorten ist. Im Laufe der Zeit scheint das Verneinungswort bn analog $\mathrm{zu} b w$ gebildet worden $\mathrm{zu}$ sein. Das könnte auch der Grund dafür sein, warum die Negation bn erst in der 18. Dynastie anzutreffen ist.

\section{Negatives prospektives $n \boldsymbol{n} \boldsymbol{s} \underline{d} \boldsymbol{m}=\boldsymbol{f}$ und $\boldsymbol{b n} \boldsymbol{s} \underline{d} \boldsymbol{m}=f^{121}$}

Das unabhängige prospektive $s \underline{d} m=f$ wird zum Ausdruck von Aufforderung, Wunsch und vorgesehenen Handlungen gebraucht. ${ }^{122}$ Dieses $s \underline{d} m=f$ bleibt in

117 El-Hamrawi (2007) $43 \mathrm{f}$.

118 Kroeber (1970) 63; Davis (1973) 151.

119 Sethe (1907) 650:3 f.

120 El-Hamrawi (2007) 45-47.

121 Die Schriftform der ägyptischen Sprachen - bis auf das Koptische - gab die Vokale nicht wieder. Wie die $s \underline{d} m=f$ - und $s \underline{d} m . n=f$-Formen vokalisiert wurden, ist nahezu unbekannt. Morphologische (wie Affixe und Geminierung), syntaktische (wie Negationen und andere Partikeln) und semantische Merkmale helfen dabei, die $s \underline{d} m=f$ - und $s \underline{d} m . n=f$-Formen voneinander zu unterscheiden.

122 Junge (2008) 150. 
der ganzen ägyptischen Sprachgeschichte unverändert. Sie wird durch die Negation $n n$ und ab der Zeit Thutmosis' III. auch durch bn negiert. ${ }^{123}$ Das subjunktivisch-prospektive $s \underline{d} m=f$ wird allerdings im Verlauf des Demotischen mit dem Hilfsverb jrj periphrasiert. ${ }^{124}$ Sie wird durch das Verneinungsverb tm negiert. Von diesen beiden prospektiven $s \underline{d} m=f$-Formen ist das nominale $s \underline{d} m=f$ zu unterscheiden, das schon in der Amarnazeit periphrasiert wird und auf zweierlei Weise (bn ... jwn3/jn oder $t m$ ) negiert werden kann. ${ }^{125}$

In dieser Untersuchung wird nur das negative unabhängige prospektive $n n / b n s \underline{d} m=f$ zur statistischen Analyse herangezogen. Das subjunktivisch-prospektive $s \underline{d} m=f$, die futurische nominale $s \underline{d} m=f$-Form und die negativen Pendants werden außer Acht gelassen.

\section{Negatives präteritales $n \boldsymbol{s} \underline{d} m=f$ und $b \boldsymbol{w} s \underline{d} m=f$}

Das $n s \underline{d} m=f$ ist das negative Gegenstück des präteritalen jw/ h' ${ }^{\prime} n s \underline{d} m . n=f$, ab der 18. Dynastie auch als $s \underline{d} m=f$ belegt. Von der 18. Dynastie an bis zur Mitte der 20. Dynastie wird diese negative $n s \underline{d} m=f$-Form in den Alltags-, literarischen und Dekorumstexten durch $b w s \underline{d} m=f$ ersetzt. Das negative $b w s \underline{d} m=f$ wird $\mathrm{ab}$ der 20. Dynastie von dem analytischen präteritalen $b w p w(j)=f s \underline{d m}$ abgelöst, das grundsätzlich in den Alltagstexten anzutreffen ist. ${ }^{126}$ Die präteritale $b w$ $p w(j)=f s \underline{d} m$-Form ist ihrerseits eine Nachfolgeform des mittelägyptischen $n$ $p 3 j=f s \underline{d} m$ und der Übergangsform $b w$ p3j= $f s \underline{d} m^{127}$

\section{Negativer Aorist $n \boldsymbol{s} \underline{d} m . n=f, n$ s $\underline{d} m=f, b w$ s $\underline{d}=. n=f, b w$ s $\underline{d} m=f$ und $b w=j r j=f s \underline{d} m$}

Der negative Aorist $n s \underline{d} m . n=f$ ist das Gegenstück der affirmativen $j w(=f) s \underline{d} m=f$ Formen, die Generalisierung, Gewohnheit und Fähigkeit ausdrücken. ${ }^{128} \mathrm{Ab}$ der Amarnazeit tritt die Verneinung $b w$ in der $n s \underline{d} m . n=f$-Form anstelle der mittelägyptischen Negation $n$ auf. Das $b w s \underline{d} m=f$ ohne das Infix . $n$ ist ebenso ab der Amarnazeit vorzufinden. Beide Formen kommen grundsätzlich in den literarischen und Dekorumstexten bis zur Regierungszeit Merenptahs (ca. 12131203 v. Chr.) vor. ${ }^{129}$ Das $n s \underline{d} m=f$ erscheint erst Ende der 18. Dynastie und bleibt in den normhierarchisch höheren Texten länger belegt. Das periphrasierte $b w$

123 Kroeber (1970) 62.

124 Junge (2008) 147.

125 S. hierzu Černý \& Groll (1993) § 27.

126 El-Hamrawi (2006) 85.

127 Erman (1933) § 776.

128 Gardiner (1957) §§ 418 und $462 \mathrm{f}$.

129 Kruchten (1999) 30; El-Hamrawi (2006) 90-92. 
$j r j=f d \underline{d} m$ ist erst unter Ramses II. in den Alltagstexten und sogar in den Dekorumstexten anzutreffen.

\section{Statistische Analyse}

Zunächst müssen einige Begriffe erklärt werden, die in den Diagrammen erscheinen, nämlich: Mittelägyptisch 1 (Mäg. $1=\square$ ), Mittelägyptisch 2 (Mäg. $2=\square$ ), Mittelägyptisch-Neuägyptisch (Mäg.-Näg. = $\square$ ), Neuägyptisch 1 (Näg. $1=\square$ ) und Neuägyptisch 2 (Näg. $2=$ ). Diese fünfteilige Struktur trifft nur auf den sog. negativen Aorist zu, der fünf verschiedene Formen aufweist. Das $n s d \underline{d} . n=f$ ist genuin mittelägyptisch; deswegen wird es in diesem Rahmen unter Mäg. 1 erfasst. Unter Mäg. 2 wird das $n s \underline{d}=f$ aufgezeichnet, das sein Infix . $n$ einbüßt. Das hybride $b w s \underline{d} m . n=f$ enthält sowohl das mittelägyptische Infix.$n$, als auch die neuägyptische Negation $b w$. Aus diesen Gründen wird es als eine Phase zwischen Mittelägyptisch und Neuägyptisch (Mäg.-Näg.) betrachtet. Als Näg. 1 wird das $b w s \underline{d} m=f$ benannt, das zwei Entwicklungsschritte zeigt, nämlich: Ausfall des Infixes.$n$ und das Verneinungswort $b w$. Die letzte Entwicklungsphase $b w$ jrj=f $s \underline{d m}$ wird als Näg. 2 gesehen.

Alle anderen herangezogenen Sprachphänomene sind entweder Mäg. 1 oder Näg. 1; ihre Formen ordnen sich klar entweder dem chronologischen Großblock „älteres Ägyptisch“ oder aber dem Großblock ,jüngeres Ägyptisch“ zu (zum „älteren“ und „jüngeren“ Ägyptisch s. o. 3.1). Die einzige Ausnahme bildet der Konjunktiv, der über drei verschiedene Entwicklungsphasen verfügt. Die erste Form $h n^{\circ} s \underline{d m}(n t f) / h n^{\circ} s \underline{d} m$ (jn Nomen) kommt in unserem Textkorpus nicht vor. Die zweite Form $h n^{\circ} n t f s \underline{d m} / h_{n} n^{\circ}$ n.tj Nomen $s \underline{d} \underline{m}$ wird unter Mäg. 2 erfasst. Das dritte Gefüge $m t w=f s \underline{d} m / m t w$ Nomen $s \underline{d} m$ ist in den jüngeren Sprachstufen verankert und wird in diesem Fall unter Näg. 1 eingereiht.

Die oben behandelten sieben Sprachphänomene werden in ausgewählten privaten Briefen und allen gut erhaltenen königlichen Stelentexten gezählt. Außer Acht gelassen werden vor allem Götternamen, wie z. B. K3-Mw.t=f, und zusammengesetzte Präpositionen, wie etwa $m-b 3 h=f$ und $r-\underline{d} r=f$, mit denen nur Possessivsuffixe auftreten können. Daher erscheint es sinnvoll, diese auszuklammern. In Bezug auf einige Texte, die neben mittelägyptischen Sprachformen Neuägyptizismen aufweisen, können die jeweils angegebenen Werte niemals endgültig sein, da mit fast jedem neuen Text die prozentualen Anteile - deutlich bei dünner Beleglage in den privaten Briefen - in gewissem Maße schwanken. Für die Zwecke unserer Untersuchung ist die Beleglage aber größtenteils ausreichend. Die periodischen Dezimalbrüche bei Prozentrechnungen in den grafischen Darstellungen werden gerundet. 
Wegen der kurzen Regierungszeiten, aber vor allem aus Mangel an privaten Briefen und königlichen Stelentexten, werden die Herrschaftszeiten Semenchkares, Tutanchamuns, Ejes und Haremhabs zusammen als Nachamarnazeit behandelt. Genauso werden die in die Zeit Ramses' I. datierten Texte gemeinsam mit denen Sethos' I. erörtert.

Ziel der Analysen ist, ein Bild von der Sprachentwicklung in beiden herangezogenen Sprachregistern zu gewinnen. Um dieses Ziel zu erreichen, werden die Sprachphänomene in den Briefen und den Stelentexten synchron und diachron ausgewertet.

\subsection{Synchrone statistische Analyse}

Die synchrone statistische Analyse zielt darauf ab, den Abstand zwischen dem sprachlichen Niveau der Alltagstexte und der Dekorumstexte zu zeigen. Die Ergebnisse werden in Diagrammen dargestellt und die absoluten Zahlen der Belege in den Balken angegeben. Darüber hinaus werden die prozentualen Anteile der mittelägyptischen und neuägyptischen Erscheinungen in der jeweiligen Textsorte addiert und durch die Gesamtzahl der belegten Sprachphänomene - optimalerweise durch die sieben behandelten Sprachphänomene dividiert, um die Ergebnisse in konkreten Zahlen zu demonstrieren.

\subsubsection{Amenophis III.}

Um den Stand der Sprache in der Voramarnazeit zu zeigen, genügt es, mit der Analyse der privaten Briefe und der königlichen Stelentexte unter Amenophis III. $\mathrm{zu}$ beginnen.

\section{Private Briefe}

Private Briefe, die definitiv unter Amenophis III. datieren, sind schwer zu identifizieren. Die drei P. Kairo CG 58053-5, deren Datierung allerdings sehr umstritten ist, ${ }^{130}$ weisen immerhin keine sprachlichen Merkmale auf, die sie später zu datieren zwingen. Im Gegenteil liegen Phänomene vor, die für die Zeit Amenophis’ III. sprechen können. Neben dem Konjunktiv hn' ntf $s \underline{d m}$ finden sich Fälle mit $h n^{\circ}=f s \underline{d m}$, die sich als Vermischung zwischen der zweiten und der dritten Phase des Konjunktivs deuten lassen.

130 Kruchten (1999) 5f. mit Anm. 24 f. 
Da in diesen drei Papyri nicht alle zu analysierenden Sprachphänomene auftreten, werden außerdem private Briefe früherer Zeiten herangezogen. Das erschwert die Vergleichbarkeit, lässt sich aber nicht vermeiden. Wenn Belege in den drei Kairener Papyri vorliegen, werden entsprechende Belege in diesen früheren Papyri nicht beachtet. Die nächstmöglichen datierbaren privaten Briefe stammen aus der Zeit Hatschepsuts und Amenophis’ II. Es werden insgesamt neun private Briefe in Betracht gezogen. ${ }^{131}$

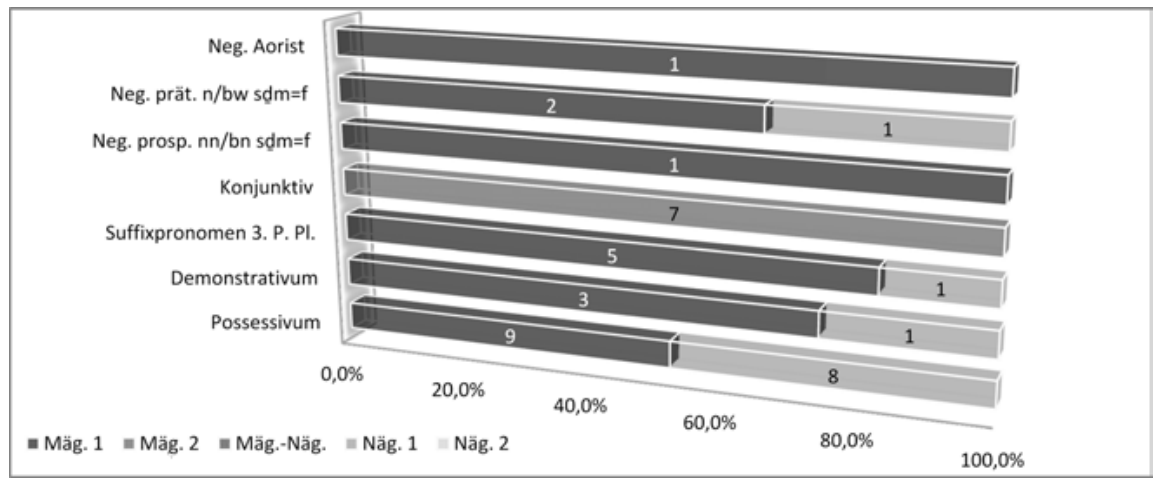

Abb. 1: Amenophis III. (Hatschepsut-Amenophis III.): private Briefe.

Die Possessivsuffixe werden in den drei Kairener Papyri nur zu 52,9\% verwendet, während die Possessivartikel zu 47,1\% eingesetzt werden. Die älteren Demonstrativa erscheinen in den drei Papyri dreimal im lexikalisierten sh $3 w$ pn, wobei $p 3 j$ nur einmal belegt ist. Das Suffix =sn wird zu 83,3\% gebraucht, das neuägyptische $=w$ ist dagegen nur $\mathrm{zu} 16,7 \%$ nachweisbar. Die zweite mittelägyptische Form des Konjunktivs ist in den Kairener Papyri siebenmal belegt. Das prospektive $n n / b n s \underline{d} m=f$ ist in der Zeit von Hatschepsut mit der Negation $n n$ nachweisbar. Das präteritale $n / b w s \underline{d} m=f$ kommt zweimal mit der Verneinung $n$ und einmal mit $b w$ vor. Die drei Belege stammen aus der Zeit von Hatschepsut und Amenophis II. In den Kairener Papyri tritt $n / b w s \underline{d m}=f$ nicht auf. Der negative Aorist ist nur als $n s \underline{d m} . n=f$ belegt.

Konkret gesagt: Die privaten Briefe in der Zeit von Hatschepsut bis Amenophis III. sind zu 82,6\% mittelägyptisch und Neuägyptizismen liegen bei 17,4\%

131 P. BM 10102, 10107, P. Louvre 3230 A/B, P. Berlin 10463, P. Leiden F 1996/1.1, P. Kairo CG 58053, CG 58054 und CG 58055. 
insgesamt. Der prozentuale Anteil der Neuägyptizismen dürfte in der Zeit von Amenophis III. allerdings höher sein.

\section{Königliche Stelentexte}

Für die Analyse der Sprache von Amenophis III. wurden elf königliche Stelentexte in Betracht gezogen. Das folgende Diagramm zeigt die Werte:

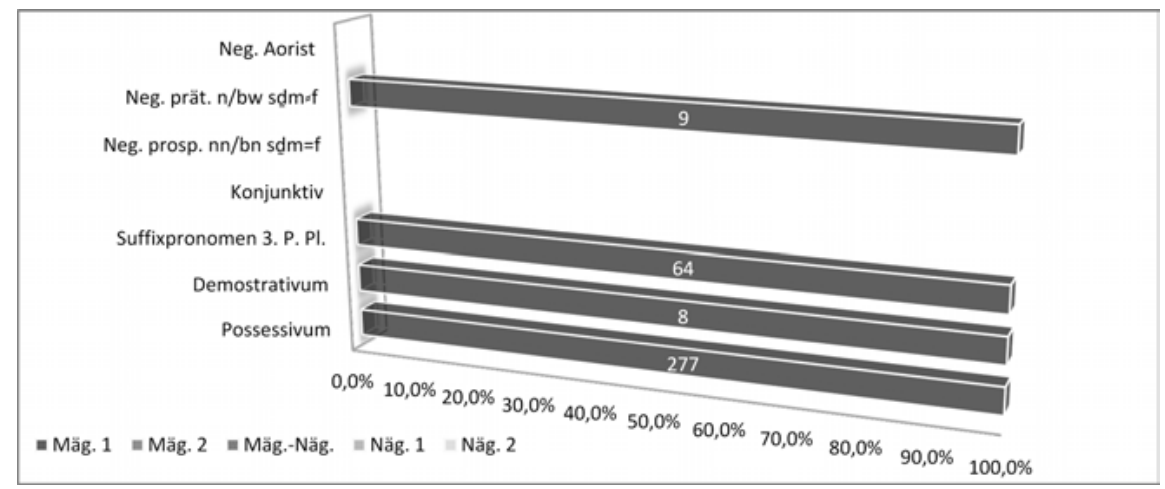

Abb. 2: Amenophis III.: königliche Stelentexte.

In den Stelentexten von Amenophis III. kommen der Konjunktiv, das prospektive $n n / b n s \underline{d} m=f$ und der negative Aorist nicht vor. Die Sprache der anderen analysierten Phänomene ist zu 100\% klassisch mittelägyptisch. Außer dem Artikel, der einige Male in den Stelen zur Anwendung kommt, sind keine Neuägyptizismen anzutreffen.

\section{Private Briefe vs. königliche Stelentexte}

Im Gegensatz zu den privaten Briefen werden die Stelentexte Amenophis' III. noch zu 100 \% in klassischem Mittelägyptisch abgefasst. Das negative prospektive $n n / b n s d m=f$ und der negative Aorist, die auf den Stelen nicht belegt sind und in den Briefen komplett mittelägyptisch sind, sind in den königlichen Texten mit den Negationen $n n$ und $n$ und in den Briefen mit $n n / b n$ und $n$ zu erwarten. 


\subsubsection{Amenophis IV./Echnaton}

\section{Private Briefe}

Unter Echnaton wurden sieben Briefe identifiziert, die aus Tell el-Amarna stammen. ${ }^{132}$

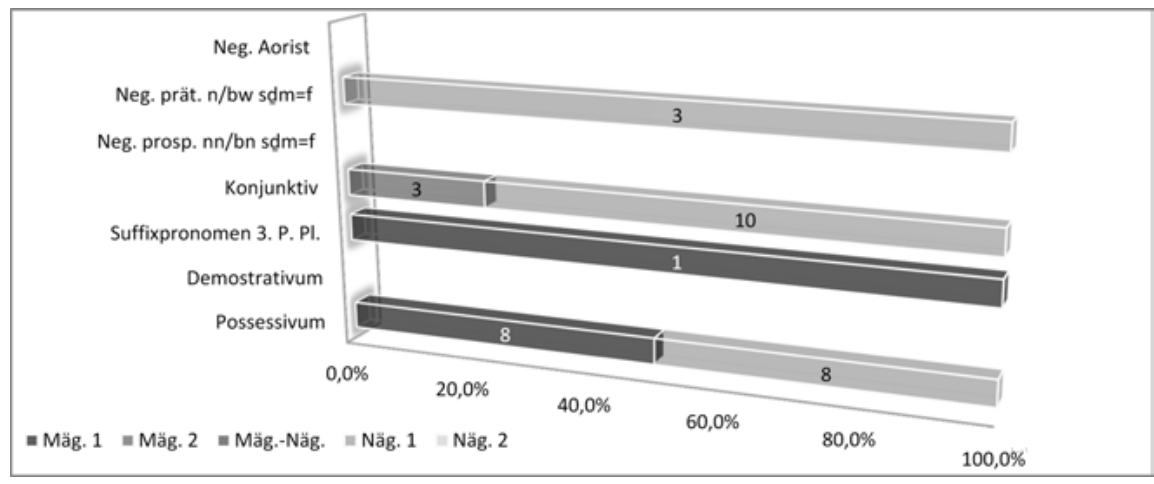

Abb. 3: Echnaton: private Briefe.

Die Demonstrativa, das negative prospektive $n n / b n s d m=f$ und der negative Aorist kommen in den Briefen nicht vor. Das Suffix der 3. P. Pl. =sn taucht nur einmal auf, das $=w$ dagegen überhaupt nicht. Da die Beleglage sehr dünn ist und deswegen unzuverlässig zu sein scheint, werden $=s n$ und $=w$ in der Analyse nicht berücksichtigt. Die anderen belegten Phänomene aber spiegeln die Veränderungen in der Sprache der Alltagstexte sehr deutlich wider: Die Possessivsuffixe sind noch zu 50,0\% belegt, während die neuägyptischen Pendants zu $50,0 \%$ erscheinen. Die zweite Konjunktivform liegt bei 23,1\%, und der neuägyptische Konjunktiv macht 76,9\% aus, wobei die beiden Formen nie in ein und demselben Text vorliegen. Das negative präteritale $n / b w s \underline{d} m=f$ tritt mit der Negation $n$ nicht auf, mit dem Verneinungswort $b w$ ist es jedoch dreimal belegt, was auf einen $100 \%$ igen Gebrauch dieser Form hindeutet.

Es lässt sich erkennen, dass der mittelägyptische Anteil in den privaten Briefen aus der Amarnazeit nur 24,3 \% beträgt. Die Neuägyptizismen belaufen sich hingegen auf 75,7\%.

132 O. CoA II,2, O. CoA II,6, O. CoA III,1, O. CoA III,3, P. Mond 1 und P. Mond 2. 


\section{Königliche Stelentexte}

Bei der Befassung mit den königlichen Stelen der Amarnazeit fällt auf, dass die Sprache der Texte aus Tell el-Amarna anders als die derjenigen aus allen anderen Orten in Ägypten zu sein scheint. Genau vergleichen lässt sich das zwar nicht. Es lässt sich einerseits nur eine sehr kleine Anzahl an Stelen aus anderen Orten finden und andererseits enthalten diese Stelen nur zwei der behandelten Sprachphänomene. Da diese Gegebenheit in diesem Rahmen von großer Bedeutung ist, werden die königlichen Stelentexte der Amarnazeit in zwei Gruppen eingeteilt.

Die eine besteht aus vier Stelen aus Heliopolis, Gebel el-Silsile, Buhen und Amada, auf denen von den untersuchten Phänomenen nur Possessivsuffixe und das Suffixpronomen =sn anzutreffen sind. Aus diesem Grund wird hier mit Vorsicht angenommen, dass diese Stelen noch in dem Stil der älteren Zeit abgefasst wurden.

Die Grenzstelen aus Tell el-Amarna, die als Gründungsproklamation der neuen Residenz Achetaton gelten, machen die andere Gruppe aus. Sie werden ihrerseits in zwei inhaltlich und sprachlich gleiche Stelentexte aufgeteilt. Der eine umfasst die früheren, im 5. Jahr errichteten Stelen K, M und X, der andere die späteren, aus den Jahren 6-8 stammenden Stelen A, B, F, J, N, Q, R, S, U und V. Beide Texte zeigen einen unerwarteten sprachlichen Umschwung, wie das nächste Diagramm zeigt:

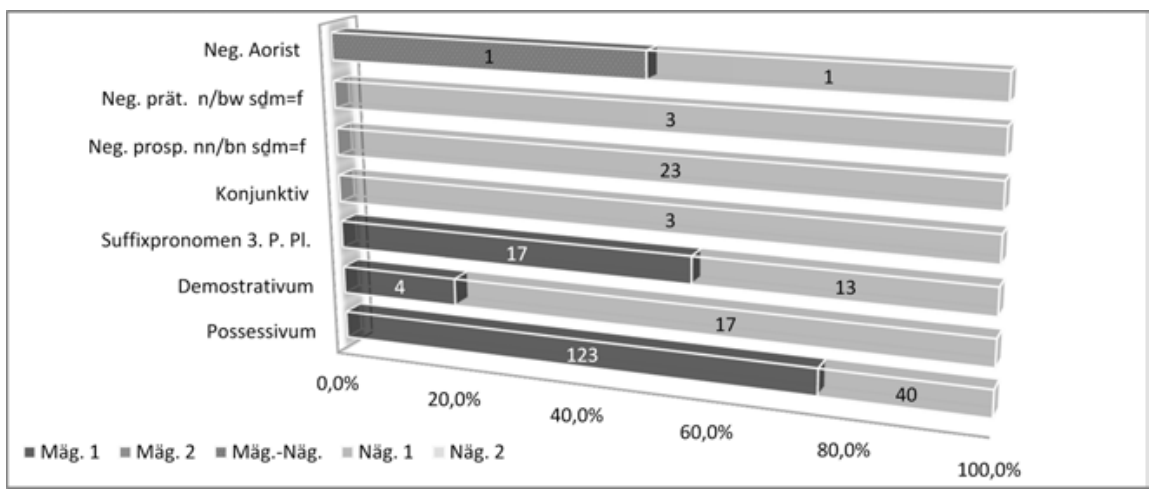

Abb. 4: Amenophis IV./Echnaton: königliche Stelentexte.

Viele Neuägyptizismen tauchen überraschend häufig auf. Die Possessivsuffixe werden nur noch zu 75,5\% benutzt, während die Possessivartikel bis zu 24,5\% Anwendung finden. Die Demonstrativa sind größtenteils neuägyptisch, zumal 
weil es sich bei den mittelägyptischen Demonstrativa, die lediglich 19,0\% ausmachen, um die lexikalisierten hrw pn und $n t r$ pn handelt. Das Suffix $=s n$ ist nur noch $\mathrm{zu} 56,7 \%$ belegt, wohingegen das neuägyptische Pendant $=w$ bis $\mathrm{zu}$ 43,3\% vorkommt. Der Konjunktiv, das prospektive $n n / b n s \underline{d} m=f$ und das präteritale $n / b w s \underline{d}=f$ zeigen ausschließlich ihre neuägyptischen Formen. Der negative Aorist ist einmal als das hybride $b w$ s $\underline{d} m . n=f$ und ein anderes Mal als $b w$ $s \underline{d} m=f$ vertreten.

Während die mittelägyptischen Sprachphänomene auf den Grenzstelen nur noch 21,6\% einnehmen, betragen die Neuägyptizismen ca. 71,3\% und die Übergangsform $7,1 \%$.

\section{Private Briefe vs. königliche Stelentexte}

Aus den beiden aufgeführten Analysen geht hervor, dass die Possessivartikel in den privaten Briefen (50,0\%) erwartungsgemäß häufiger als auf den Grenzstelen von Tell el-Amarna (24,5\%) erscheinen. Trotzdem ist das Vorkommen dieses neuägyptischen Phänomens in den Dekorumstexten überraschend hoch. In den privaten Briefen tritt der Konjunktiv in seiner zweiten und dritten Form auf, wobei der neuägyptische Konjunktiv mehr als dreimal so hoch belegt ist. Auf Stelen von Tell el-Amarna findet dagegen nur der neuägyptische Konjunktiv Verwendung. Das präteritale $n / b w s \underline{d} m=f$ findet sich sowohl in den privaten Briefen als auch auf den Grenzstelen von Tell el-Amarna ausschließlich in seiner neuägyptischen Form.

In konkreten Zahlen kann festgehalten werden, dass die privaten Briefe $\mathrm{zu}$ 24,3\% mittelägyptisch und $\mathrm{zu} 75,7 \%$ neuägyptisch sind, während die Grenzstelen zu nur 21,6\% mittelägyptisch, 7,1\% hybrid und zu 71,3\% neuägyptisch sind. Das bedeutet, dass die Grenzstelen etwa so viel Neuägyptizismen wie die privaten Briefe dieser Zeit enthalten.

\subsubsection{Nachamarnazeit}

\section{Private Briefe}

Aus der Nachamarnazeit sind bedauerlicherweise kaum private Briefe erhalten. Herangezogen werden können nur drei kleine Texte, die grob ans Ende der 18. Dynastie datiert sind. ${ }^{133}$ 


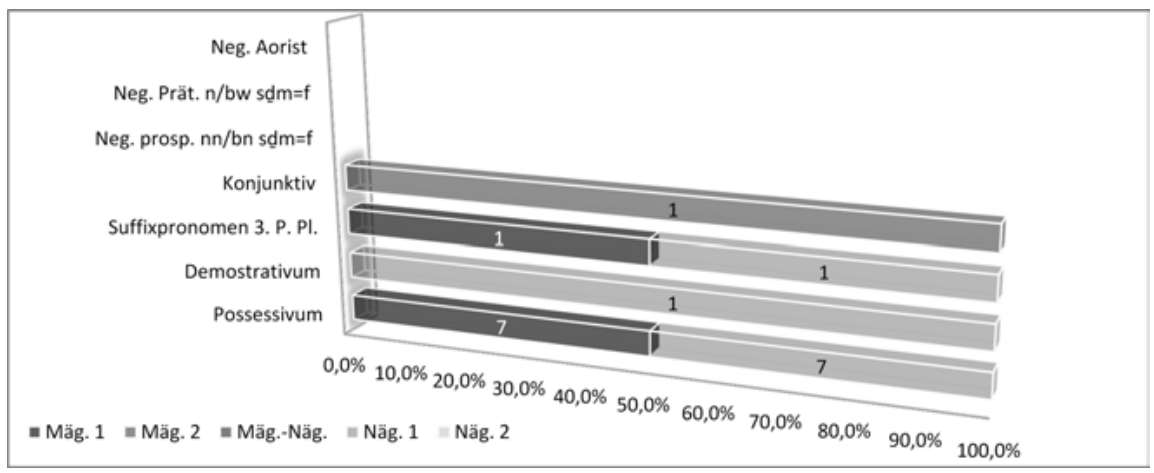

Abb. 5: Nachamarnazeit: private Briefe.

Possessivsuffixe und Possessivartikel werden gleichermaßen gebraucht. Neuägyptische Demonstrativa kommen nur einmal, allerdings als Personenname $P_{3 j}$, vor, während die älteren nicht belegt sind. Da die älteren in diesem Zeitraum fast ausschließlich lexikalisiert erscheinen, wird dieser Beleg nicht ausgeklammert. Die Personalsuffixe der 3. P. Pl. =sn und $=w$ sind jeweils einmal vertreten. Der Konjunktiv ist in seiner zweiten mittelägyptischen Form einmal zu finden. In der Regel ist eher die neuägyptische Konjunktivform als das mittelägyptische Pendant zu erwarten, deswegen wird dieser Beleg außer Acht gelassen. ${ }^{134}$ Abgesehen von diesen wahrscheinlich unverlässlichen prozentualen Anteilen, könnte die Alltagssprache der Nachamarnazeit nicht viel anders als die der Amarnazeit sein.

\section{Königliche Stelentexte}

In der Nachamarnazeit sind acht königliche Stelentexte $\mathrm{zu}$ identifizieren, die für diese Untersuchung in Betracht kommen. Drei davon sind aus der Zeit Tutanchamuns, einer aus der Zeit Ejes und die restlichen vier aus der Zeit Haremhabs. Bei der Beschäftigung mit diesen Texten fällt sofort auf, dass sich die Sprache des Haremhab-Dekrets deutlich abhebt. Aus diesem Grund werden zunächst die sieben Stelentexte ohne das Dekret statistisch ausgewertet.

Mit Ausnahme des Konjunktivs und des negativen prospektiven $n n / b n$ $s \underline{d} m=f$ sind alle anderen Phänomene in den sieben Texten vertreten. Sie stehen

134 Es könnte allerdings sein, dass es sich hierbei um einen Rückgriff auf die Form der Voramarnazeit handelt, was jedoch wegen der sehr dünnen Beleglage in den Briefen und der Nachweise des neuägyptischen Konjunktivs im Haremhab-Dekret nicht beurteilt werden kann. 


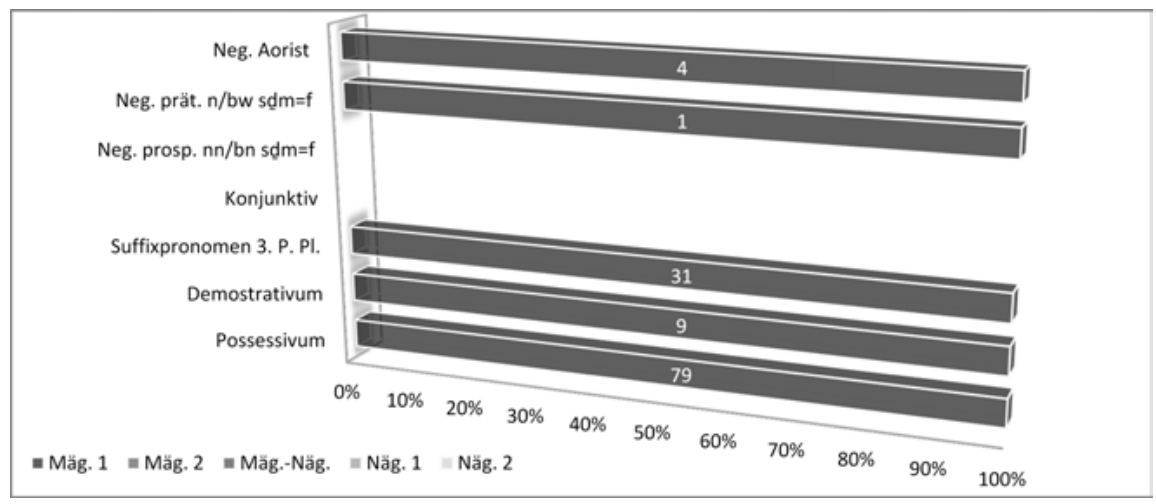

Abb. 6: Nachamarnazeit: königliche Stelentexte o. das Haremhab-Dekret.

eindeutig in der klassischen mittelägyptischen Sprachtradition. Jegliche Neuägyptizismen fehlen in den Texten, wie Abb. 6 veranschaulicht.

Sehr auffällig ist auch die Verwechslung zwischen den Negationen $n$ und $n n$ in dem negativen Aorist $n s \underline{d m .} n=f$ auf der Restaurationsstele, ${ }^{135}$ obwohl es sich dabei um den negativen Aorist derselben Verben handelt und die Textstellen teilweise aufeinanderfolgen.

Die Analyse des Haremhab-Dekrets allein ergibt folgende prozentuale Werte:

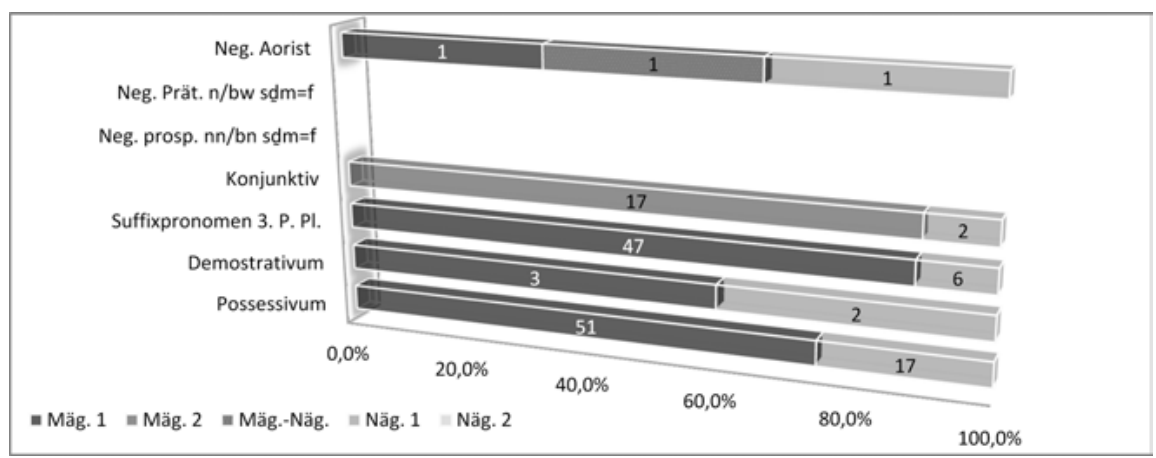

Abb. 7: Nachamarnazeit: Haremhab-Dekret.

$135 n$ hpr.n rwd.t=sn $n b$ (Helck 1958, 2027:14) $n\{n\}$ jj.n=f [rsj] (Helck 1958, 2027:16), $n$ jj.n=f rsj (Helck 1958, 2027:18) $n\{n\}$ hpr.n $n=f$ sn.w (Helck 1958, 2032:4). 
Possessivsuffixe werden noch zu 75,0\% und Possessivartikel zu 25,0 \% eingesetzt. Ältere Demonstrativa finden zu 60,0\% und jüngere bis zu 40,0\% Anwendung. Das Suffix $=s n$ wird $\mathrm{zu} 88,7 \%$ gebraucht, das $=w$ hingegen nur zu $11,3 \%$. Im Dekret sind die zweite und dritte Form des Konjunktivs belegt, ohne erkennbaren Unterschied im Gebrauch. Das zweite Gefüge ist sowohl mit unabhängigen Pronomina als auch mit Nomen anzutreffen. Dabei sind zwei Konstruktionen zu unterscheiden: Ohne die und mit der Präposition $h r$. Die eine entspricht dem Konjunktiv der zweiten Phase. Die andere stimmt entweder mit der ersten Form, allerdings zusätzlich mit der Präposition $h r$ vor dem Infinitiv, überein oder besteht aus der Präposition hnn' und sog. Präsens I. Diese kommen 17-mal im Dekret vor und machen 89,5\% der Belege aus. Der neuägyptische Konjunktiv findet sich dagegen nur zweimal im Text, wobei die Präposition $h r$ vor dem Infinitiv einmal auftritt. Von dem negativen Aorist sind die Formen $n$ $s \underline{d} m . n=f, b w s \underline{d} m . n=f$ und $b w s \underline{d}=f$ jeweils einmal anzutreffen. Die Belege für $n$ $s \underline{d}$. $n=f$ und $b w$ sdm.n=f kommen mit gmj „finden“ vor: $n$ gmj.n.tw und $b w$ gmj.n.tw. ${ }^{136}$ Diese Unregelmäßigkeiten im Dekret sind auf sprachliche Unsicherheit des Schreibers zurückzuführen.

Wird dieses Dekret gemeinsam mit den anderen Stelentexten dieser Zeitspanne analysiert, so ergeben sich prozentuale Anteile, die zu 88,0\% mittelägyptisch, 2,4\% hybride Übergangsphase und 9,6\% neuägyptisch sind, wie das folgende Diagramm veranschaulicht:

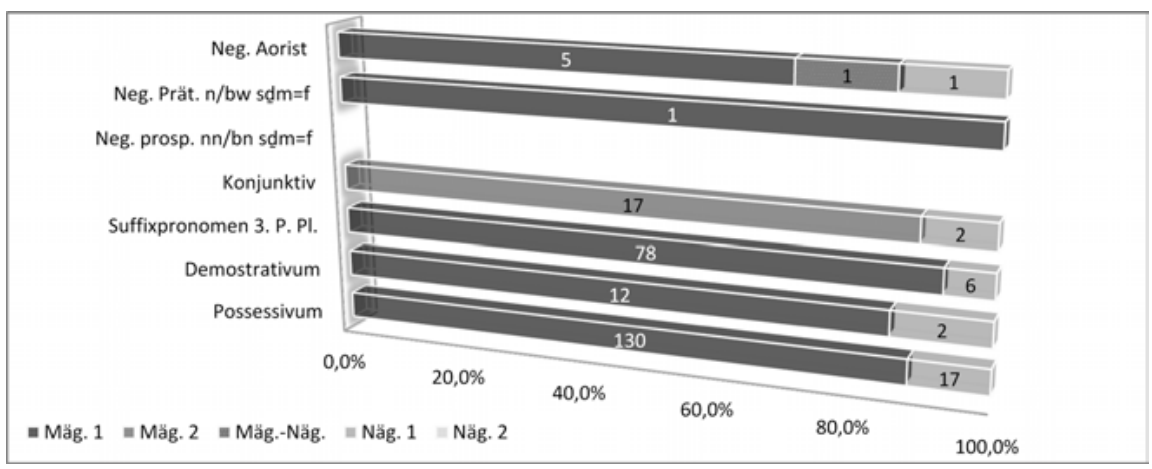

Abb. 8: Nachamarnazeit: königliche Stelentexte.

\section{Private Briefe vs. königliche Stelentexte}

Wird das Haremhab-Dekret zunächst ausgespart, so sind die Stelentexte gänzlich mittelägyptisch, die Briefe dagegen zeigen neben mittelägyptischen neu- 
ägyptische Formen. Das Dekret selbst enthält deutlich weniger Neuägyptizismen, wobei der neuägyptische Konjunktiv nur dort auftaucht.

\subsubsection{Ramses I.-Sethos I.}

\section{Private Briefe}

Aus der Zeit Ramses' I.-Sethos' I. wurden fünf Briefe ${ }^{137}$ identifiziert, in denen fünf der sieben Sprachphänomene belegt sind, wie im Folgenden sichtbar ist:

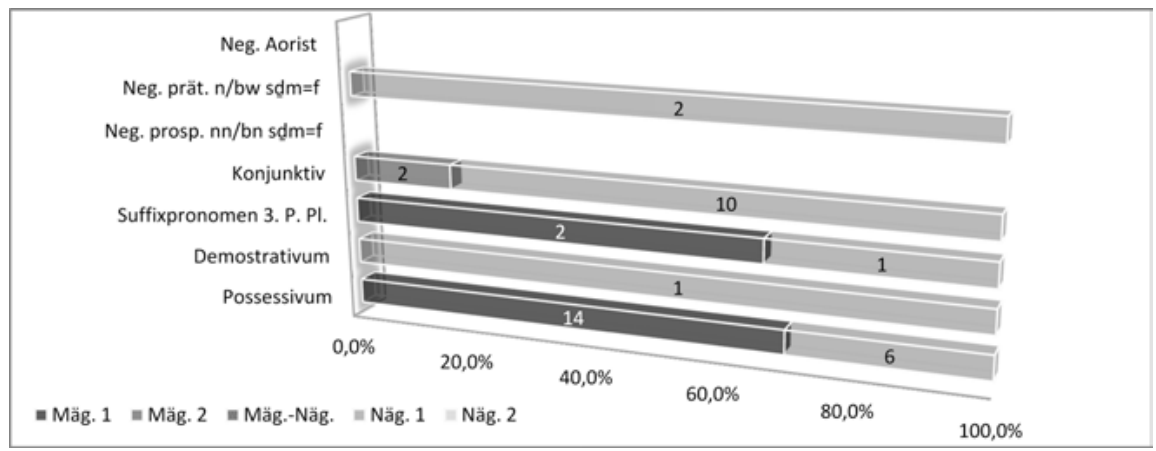

Abb. 9: Ramses I.-Sethos I.: private Briefe.

Die Possessivsuffixe werden zu 70,0 \% gebraucht, wobei viele mit Körperteilen bzw. in lexikalisierten Gefügen erscheinen, die Possessivartikel sind hingegen zu 30,0 \% vertreten. Die älteren Demonstrativa kommen nicht vor, die jüngeren treten indes nur einmal auf. Das Suffix =sn ist zweimal eingesetzt, während $=w$ nur einmal zu finden ist. Der neuägyptische Konjunktiv macht $83,3 \%$ aus, demgegenüber taucht die zweite mittelägyptische Form nur zu 16,7\%, auf. Das negative präteritale $n / b w s \underline{d} m=f$ ist nur mit der Negation $b w$ präsent.

Dem Ausgeführten kann entnommen werden, dass die privaten Briefe aus der Zeit Ramses' I. und Sethos’ I. zu 69,4 \% neuägyptisch und zu 30,6 \% mittelägyptisch sind.

\section{Königliche Stelentexte}

Aus der Zeit Ramses' I. wurden drei und unter Sethos I. 22 Stelen identifiziert. Die Analyse der Stelentexte der beiden Könige ergibt folgende Werte:

137 P. Kairo CG 58057 und CG 58058, P. Northumberland 1, O. Osireion 2 und P. Turin 1977. 


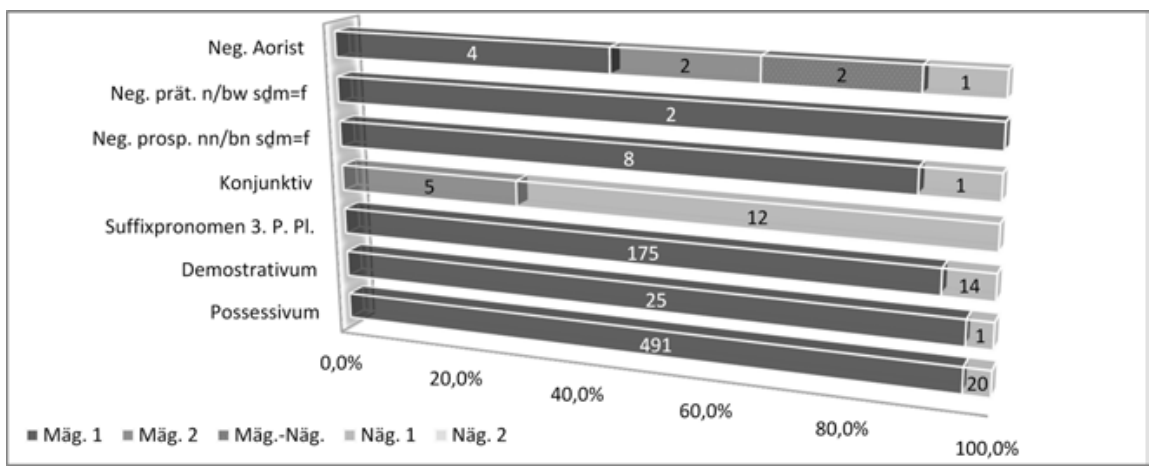

Abb. 10: Ramses I.-Sethos I.: königliche Stelentexte.

Possessivsuffixe werden $\mathrm{zu}$ 94,1\% gebraucht, Possessivartikel dagegen nur zu 3,9\%. Ältere Demonstrativa sind zu 96,2\% und jüngere Pendants nur einmal $(3,8 \%)$ in direkter Rede verwendet. Das Personalsuffix =sn ist zu 92,6\% belegt, das $=w$ erscheint nur zu 7,4\%. Der Konjunktiv, der lediglich im Dekret von Nauri anzutreffen ist, ist in seiner zweiten Form zu 29,4\% belegt. Der neuägyptische Konjunktiv tritt zu 70,6\% auf. Sehr auffällig sind die Konjugationsbasen $m t w$ und $m-d j$, zwischen deren Vorkommensweisen kein Unterschied zu erkennen ist. ${ }^{138}$ Manchmal kommt $m$-dj sogar vor derselben syntaktischen und lexikalischen Konstruktion wie $h n^{\circ}$ vor. ${ }^{139}$ Im negativen prospektiven $n n / b n s \underline{d m}=f$ wird in der Regel die Negation $n n(88,9 \%)$ benutzt, $b n$ ist hingegen nur einmal $(11,1 \%) \mathrm{zu}$ finden. Das negative präteritale $n / b w s \underline{d} m=f$ ist nur mit $n$ zu finden. Der negative Aorist zeigt vier verschiedene Formen: $n s \underline{d} m . n=f$ ist viermal, $n s \underline{d} m=f$ zweimal, $b w s \underline{d} m . n=f$ zweimal und $b w s \underline{d} m=f$ einmal belegt.

Aus dem Erwähnten lässt sich ersehen, dass 81,4\% der behandelten Sprachphänomene mittelägyptisch und 15,4\% neuägyptisch sind, die Übergangsform macht nur 3,2\% aus.

\section{Private Briefe vs. königliche Stelentexte}

In beiden Textsorten werden sowohl Possessivsuffixe als auch Possessivartikel verwendet, wobei die Possessivsuffixe in den Stelentexten $\mathrm{zu}$ 96,1\% und in den Briefen dagegen nur zu 70,0\% gebraucht sind. Demonstrativa sind in den Briefen nur neuägyptisch (einmal) belegt, während auf den Stelen fast ausschließlich $(96,2 \%)$ die mittelägyptischen verwendet werden. Die Personal- 
suffixe $=s n$ und $=w$ kommen in beiden Textsorten vor. Das $=s n$ wird in den Briefen $\mathrm{zu} 66,7 \%$ und in den Stelentexten $\mathrm{zu} 92,6 \%$ angewandt, ansonsten ist $=w$ anzutreffen. Der Konjunktiv ist in beiden Textsorten vertreten, wobei der neuägyptische in den Briefen häufiger benutzt wird. Das negative präteritale $n / b w s \underline{d m}=f$ ist in den Briefen ausschließlich mit $b w$ und in den Stelentexten nur mit $n$ zu finden.

Konkret gesagt: Private Briefe sind zu 69,4\% neuägyptisch und nur noch zu 30,6\% mittelägyptisch. Im Gegensatz dazu sind die königlichen Stelentexte nur zu 15,4\% neuägyptisch, während die Mehrheit der Sprachphänomene $(81,4 \%)$ mittelägyptisch ist.

\subsubsection{Ramses II.}

\section{Private Briefe}

Aus der langen Regierungszeit Ramses' II. werden nur 17 private Briefe ${ }^{140}$ herangezogen, in denen alle Sprachphänomene häufig vorkommen. Die Analyse ergibt Folgendes:

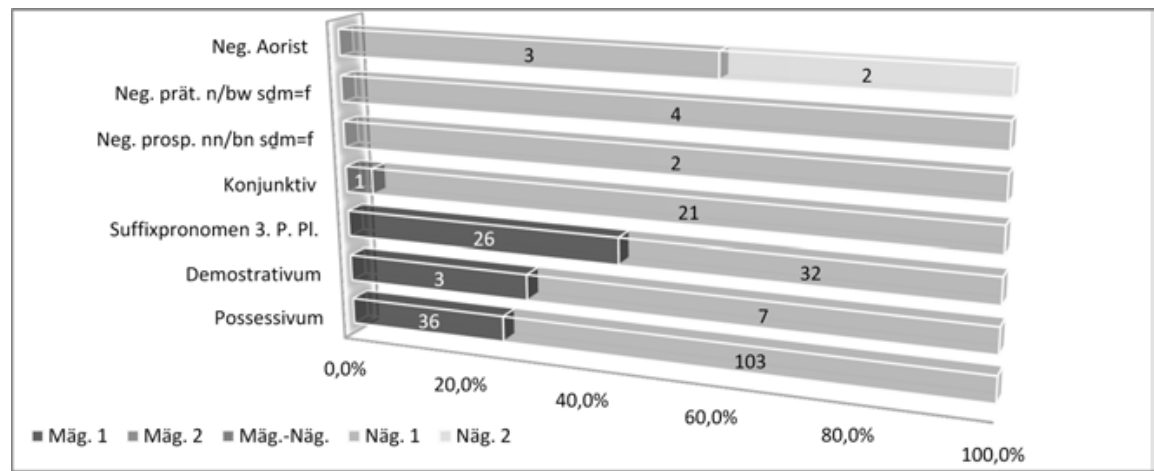

Abb. 11: Ramses II.: private Briefe.

Possessivsuffixe sind $\mathrm{zu}$ 25,9\% - größtenteils in lexikalisierten Bildungen und Possessivartikel zu 74,1 \% belegt. Demonstrativa liegen dreimal in den Briefen vor. Bei zwei davon handelt es sich um die lexikalisierte Verbindung sḩ $3 w$ $p n$, und bei dem dritten wird es mit dem Artikel $p_{3}$ kombiniert: $p 3$ hr $p n$. Die

140 O. Berlin 12398, O. Kairo CG 25832, O. DeM 114, O. Gardiner 0114 und 0125, O. Toronto A 11:Recto 1-30, Verso 1-25, P. Berlin 14424a und 14433a-i, P. Leiden I.349, P. Anastasi VIII und IX, P. Kairo CG 58056 und CG 58059, P. Ermitage 1117 und 1118. 
neuägyptischen Demonstrativa werden zu 70,0\% verwendet. Das Personalsuffix $=s n$ wird noch $\mathrm{zu} 44,8 \%$ und das $=w$ bis $\mathrm{zu}$ 55,2\% eingesetzt. ${ }^{141}$ Der zweite mittelägyptische Konjunktiv kommt nur ein einziges Mal vor, der neuägyptische dagegen ist 21-mal belegt. Das prospektive $n n / b n s d m=f$ und das präteritale $n / b w s \underline{d} m=f$ werden nur mit $b n$ respektive $b w$ bezeugt. Der neuägyptische negative Aorist $b w s \underline{d}=f$ ist dreimal belegt, während die letzte Entwicklungsphase $b w$ jrj $=f s \underline{d} m$ zweimal gebraucht wird.

Die privaten Briefe aus der Zeit Ramses’ II. sind also zu 85,0\% neuägyp-

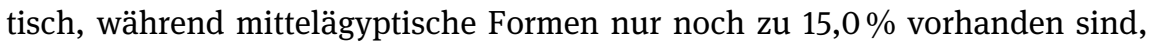
sie sind aber größtenteils in lexikalisierten Wortverbindungen anzutreffen.

\section{Königliche Stelentexte}

Aus der Zeit Ramses' II. stehen 40 Stelen zur Verfügung, die in drei Gruppen einzuteilen sind. Auf der einen Seite sind Stelen anzutreffen, die gar keinen der hier behandelten Neuägyptizismen enthalten. Auf der anderen Seite finden sich solche, in deren Texten nur Neuägyptizismen wie Possessivartikel, jüngere Demonstrativa oder das Personalsuffix $=w$ vorkommen. Bei der dritten Gruppe handelt es sich um einige mit vielen Neuägyptizismen.

Die erste Gruppe von 15 Texten ist weder zeitlich noch örtlich einzuordnen, außer einer Stele (BM 440, Gisa, 1. Regierungsjahr). Allen Stelen gemeinsam ist, dass sie jeweils einen rhetorischen Text tragen. Sie weisen vier der Sprachphänomene auf, nämlich Possessivum, Demonstrativum, Personalsuffix der 3. P. Pl. und der negative Aorist. Alle sind zu $100 \%$ mittelägyptisch, wie dieses Diagramm zeigt:

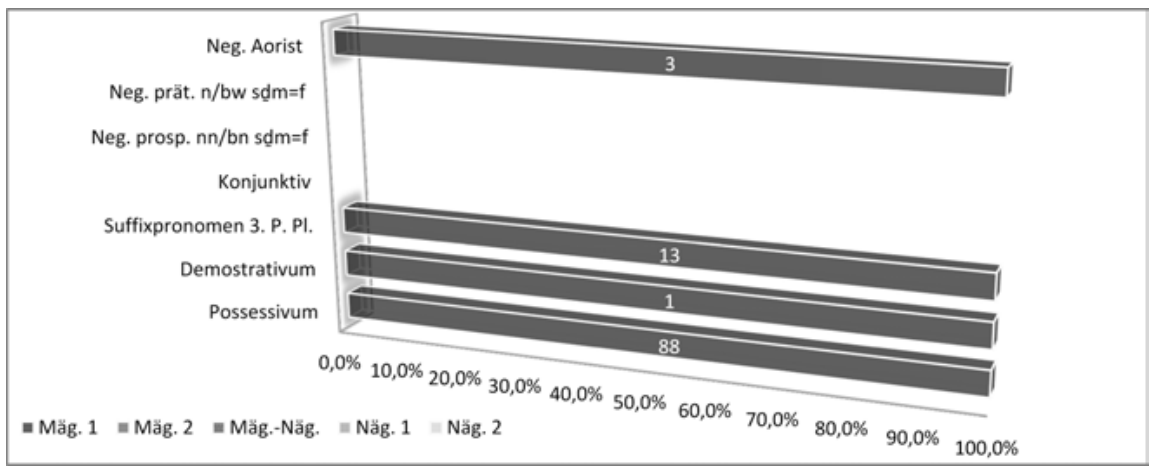

Abb. 12: Ramses II.: königliche Stelentexte I.

141 Die Mehrheit der Belege stammt aus P. Anastasi VIII und IX. Im P. Anastasi VIII kommt $=s n$ zwölfmal und $=w$ nur dreimal vor. Während im P. Anastasi IX das Suffix $=s n$ nur einmal 
Die zweite Gruppe umfasst acht Stelentexte mit bestimmten Neuägyptizismen; die neuägyptischen Negationen bleiben aber aus. Belegt sind neuägyptische Phänomene wie die Possessivartikel (2,9\%) und das Personalsuffix $=w(17,1 \%)$. Ansonsten ist keiner der hier behandelten Neuägyptizismen bezeugt. Das $n s \underline{d}=f$ des negativen Aoristes ist einmal neben der $n$ s $\underline{d} m . n=f$-Form (zweimal) belegt. Das folgende Diagramm soll dies veranschaulichen:

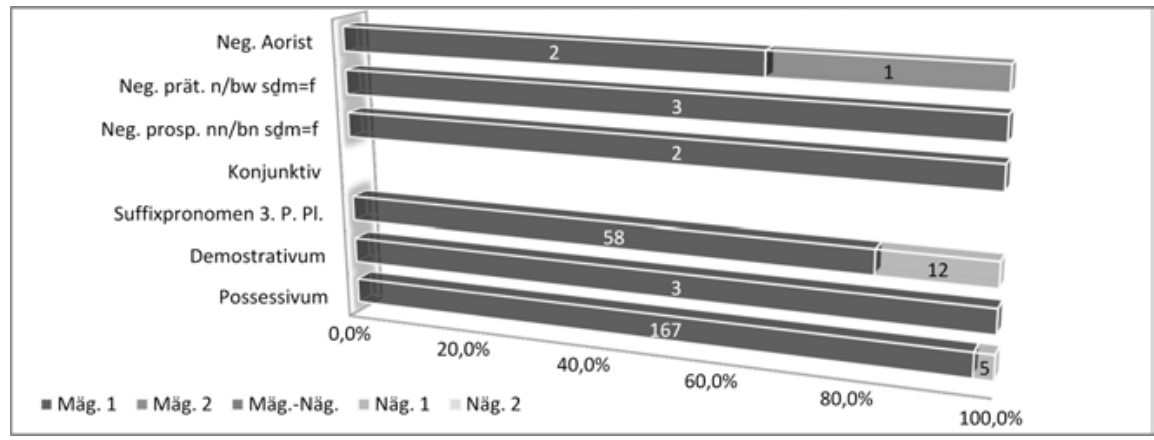

Abb. 13: Ramses II.: königliche Stelentexte II.

Bei der dritten Gruppe handelt es sich um 17 Stelen, die in acht Stelentexte einzuteilen sind. Die Analyse aller Texte dieser Gruppe ergibt folgende Werte:

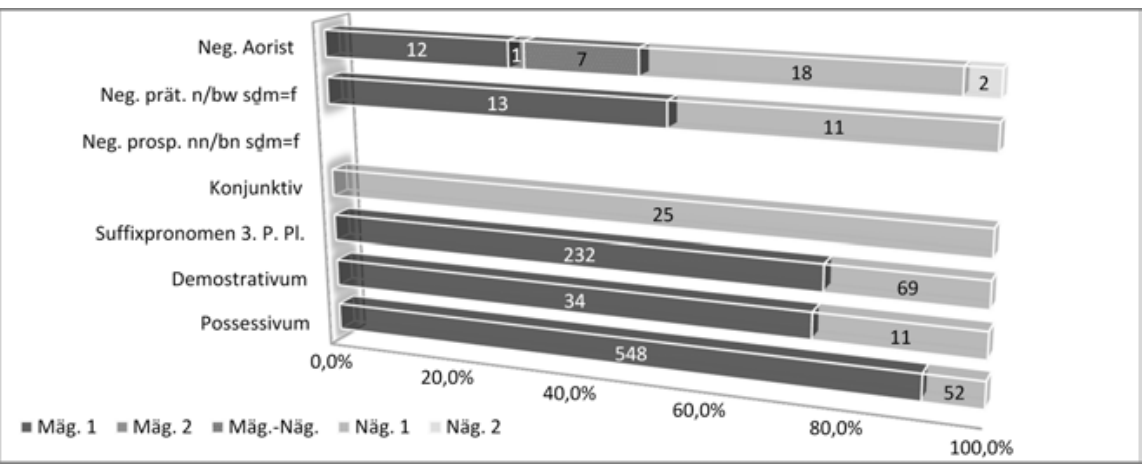

Abb. 14: Ramses II.: königliche Stelentexte III.

auftaucht, wird $=w$ 21-mal verwendet. Im letzten Brief befinden sich die einzigen Belege für den Aorist $b w$ jrj $j=f \underline{d} d m$, aber es treten auch die Possessivartikel zu 92,6\% auf. Die Sprache des P. Anastasi IX ist sehr fortgeschritten neuägyptisch. Dies könnte entweder mit einem unterschiedlichen Bildungsniveau der Schreiber oder mit zwei verschiedenen Dialekten begründet werden. 
Possessivsuffixe werden bis $\mathrm{zu} 91,3 \%$ und Possessivartikel nur zu 8,7\% gebraucht. Demonstrativa sind zu 75,6\% mittelägyptisch und noch zu 24,4\% neuägyptisch. Das Personalsuffix =sn ist $\mathrm{zu} 77,1 \%$ belegt, während =w nur zu 22,9\% vorkommt. In den Stelentexten ist der Konjunktiv ausschließlich neuägyptisch und erscheint fast nur - mit einer einzigen Ausnahme - in dem Hethitervertrag. Das negative präteritale $n / b w s \underline{d} m=f$ bedient sich der Verneinung $n \mathrm{zu} \mathrm{54,2 \%}$

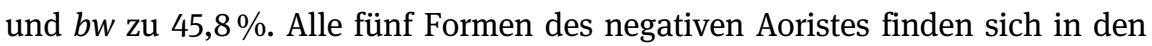
Texten. Das $n$ s dm. $n=f$ ist $\mathrm{zu} 30,0 \%, n s \underline{d} m=f \mathrm{zu} 2,5 \%, b w$ s $\underline{d} m . n=f \mathrm{zu} 17,5 \%, b w$ $s \underline{d} m=f \mathrm{zu} 45,0 \%$ und das $b w$ jrj $s \underline{d} m=f \mathrm{zu} 5,0 \%$ (Hethitervertrag) vertreten.

Die Stelentexten der dritten Gruppe prägen die statistischen Werte der gesamten Stelentexte Ramses' II. in hohem Grade, wie im Folgenden gezeigt wird:

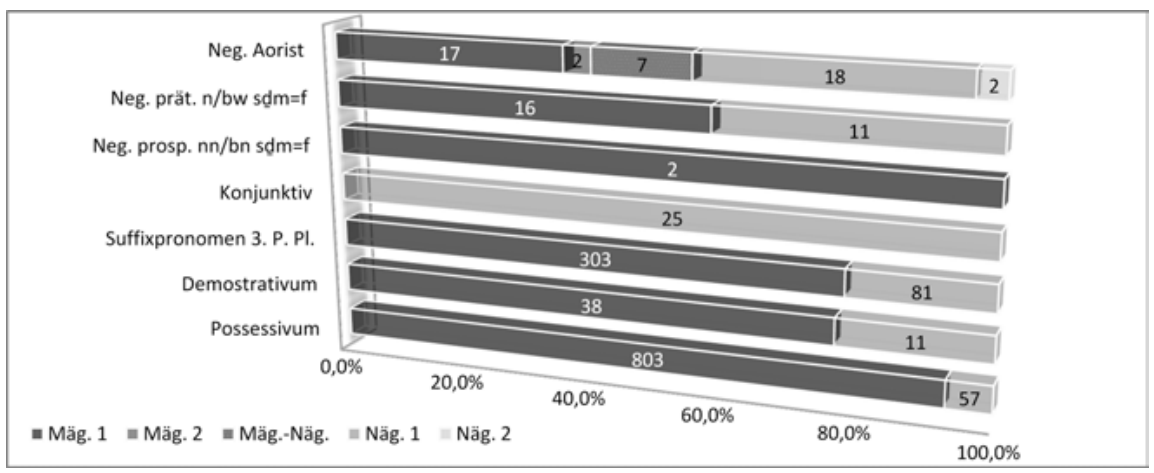

Abb. 15: Ramses II.: königliche Stelentexte IV (Gesamtwert).

Die Possessiva sind zu 93,4\% mittelägyptisch und 6,6\% neuägyptisch. Die älteren Demonstrativa sind $\mathrm{zu} 77,6 \%$ und die jüngeren $22,4 \%$, $=s n 78,9 \%$ und $=w$ $21,1 \%$ belegt. Der Konjunktiv ist genau wie in der dritten Gruppe zu $100 \%$ neuägyptisch. Das negative prospektive $n n / b n s \underline{d m}=f$ ist nur mit $n n$ bezeugt. Das negative präteritale $n s \underline{d} m=f$ ist zu $59,3 \%$ belegt, während das $b w s \underline{d} m=f$ zu 40,7\% auftaucht. Der negative Aorist macht in der königlichen Stelentexten Ramses' II. von seinen fünf Formen Gebrauch. Das $n$ sdm. $n=f$ wird zu 37,0 \%, das $n s \underline{d} m=f \mathrm{zu} 4,3 \%$, das hybride $b w s \underline{d m} . n=f \mathrm{zu} 15,2 \%$, das neuägyptische

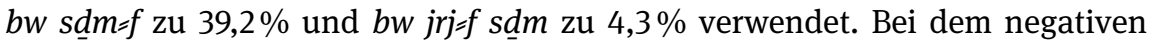
präteritalen $n s \underline{d} m=f$ und dem negativen Aorist $n s \underline{d m} . n=f$ wird zwischen den Negationen $n$ und $n n$ gewechselt.

Kurz zusammengefasst: Während auf einigen Stelen alle Formen noch mittelägyptisch sind, sind auf anderen größtenteils mittelägyptische und wenige neuägyptische Formen anzutreffen und auf dritten so viel neuägyptische wie mittelägyptische Sprachphänomene zu finden. Insgesamt lässt sich ersehen, dass die Stelentexte zu 64,3\% mittelägyptisch und $\mathrm{zu}$ 33,5\% neuägyptisch sind. Die Übergangsform macht nur 2,2\% aus. 


\section{Private Briefe vs. königliche Stelentexte}

Beim Vergleich beider Textsorten wird ersichtlich, dass die Possessiva, Demonstrativa und Suffixpronomina der 3. P. Pl. sowohl mittelägyptisch als auch neuägyptisch sind, wobei die neuägyptischen Sprachformen in den Briefen mehr da sind. Während der Konjunktiv auf den Stelen komplett neuägyptisch ist, ist er in den Briefen noch zu 4,5\% mittelägyptisch. Im prospektiven $n n / b n$ $s \underline{d} m=f$ wird in den Stelentexten nur $n n$ verwendet, während die Briefe nur von $b n$ Gebrauch machen. In den Briefen wird im negativen präteritalen $n / b w s \underline{d m}=f$ ausschließlich $b w$ benutzt, in den königlichen Texten dagegen treten beide auf, wobei $n$ noch zu 57,6\% verwendet wird. Der negative Aorist ist in den Briefen völlig neuägyptisch, auf den Stelen ist er hingegen zu 41,3\% mittelägyptisch, 43,5\% neuägyptisch und 15,2\% hybrid ist.

\subsection{Diachrone statistische Analyse}

Nach diesen synchronen statistischen Analysen der Sprache der privaten Briefe und der königlichen Stelentexte in der Zeit von Amenophis III. bis Ramses II. werden hier zunächst alle prozentualen Werte der behandelten Sprachphänomene addiert und zusammengestellt:

Tab. 1: Prozentuale Anteile der mittel- und neuägyptischen Sprachphänomene in den privaten Briefen und den königlichen Stelentexten von Amenophis III. bis Ramses II.

\begin{tabular}{|c|c|c|c|c|c|c|c|}
\hline Gesamtwert aller Texte & Mäg. 1 & Mäg. 2 & Mäg. & $\begin{array}{l}\text { Mäg.- } \\
\text { Näg. }\end{array}$ & Näg. 1 & Näg. 2 & Näg. \\
\hline $\begin{array}{l}\text { Amenophis III.: private Briefe } \\
\text { Amenophis III.: königliche } \\
\text { Stelentexte }\end{array}$ & $\begin{array}{r}68,3 \% \\
100,0 \%\end{array}$ & $\begin{array}{r}14,3 \% \\
0,0 \%\end{array}$ & $\begin{array}{l}82,6 \\
0,0 \%\end{array}$ & $\begin{array}{l}0,0 \% \\
0,0 \%\end{array}$ & $\begin{array}{r}17,4 \% \\
0,0 \%\end{array}$ & $\begin{array}{l}0,0 \% \\
0,0 \%\end{array}$ & $\begin{array}{r}17,4 \% \\
0,0 \%\end{array}$ \\
\hline $\begin{array}{l}\text { Echnaton: private Briefe } \\
\text { Echnaton: königliche Stelentexte }\end{array}$ & $\begin{array}{l}16,6 \% \\
21,6 \%\end{array}$ & $\begin{array}{l}7,7 \% \\
0,0 \%\end{array}$ & $\begin{array}{l}24,3 \\
21,6\end{array}$ & $\begin{array}{l}0,0 \% \\
7,1 \%\end{array}$ & $\begin{array}{l}75,7 \% \\
71,3 \%\end{array}$ & $\begin{array}{l}0,0 \% \\
0,0 \%\end{array}$ & $\begin{array}{l}75,7 \% \\
71,3 \%\end{array}$ \\
\hline $\begin{array}{l}\text { Nachamarnazeit: private Briefe } \\
\text { Nachamarnazeit: kgl. Stelentexte } \\
\text { o. Haremhab-Dekret }\end{array}$ & $\begin{array}{c}33,3 \\
100,0 \%\end{array}$ & $\begin{array}{l}0,0 \% \\
0,0 \%\end{array}$ & $\begin{array}{r}33,3 \% \\
100,0 \%\end{array}$ & $\begin{array}{l}0,0 \% \\
0,0 \%\end{array}$ & $\begin{array}{r}66,7 \% \\
0,0 \%\end{array}$ & $\begin{array}{l}0,0 \% \\
0,0 \%\end{array}$ & $\begin{array}{r}66,7 \% \\
0,0 \%\end{array}$ \\
\hline $\begin{array}{l}\text { Nachamarnazeit: Haremhab- } \\
\text { Dekret }\end{array}$ & $51,4 \%$ & $17,9 \%$ & $69,3 \%$ & $6,7 \%$ & $24,0 \%$ & $0,0 \%$ & $24,0 \%$ \\
\hline $\begin{array}{l}\text { Nachamarnazeit: königliche } \\
\text { Stelentexte insgesamt }\end{array}$ & $73,1 \%$ & $14,9 \%$ & $88,0 \%$ & $2,4 \%$ & $9,6 \%$ & $0,0 \%$ & $9,6 \%$ \\
\hline $\begin{array}{l}\text { Ramses I.-Sethos I.: private Briefe } \\
\text { Ramses I.-Sethos I.: königliche } \\
\text { Stelentexte }\end{array}$ & $\begin{array}{l}27,3 \% \\
74,0 \%\end{array}$ & $\begin{array}{l}3,3 \% \\
7,4 \%\end{array}$ & $\begin{array}{l}30,6 \% \\
81,4 \%\end{array}$ & $\begin{array}{l}0,0 \% \\
3,2 \%\end{array}$ & $\begin{array}{l}69,4 \% \\
15,4 \%\end{array}$ & $\begin{array}{l}0,0 \% \\
0,0 \%\end{array}$ & $\begin{array}{l}69,4 \% \\
15,4 \%\end{array}$ \\
\hline $\begin{array}{l}\text { Ramses II.: private Briefe } \\
\text { Ramses II.: königliche Stelentexte }\end{array}$ & $\begin{array}{l}14,4 \% \\
63,7 \%\end{array}$ & $\begin{array}{l}0,6 \% \\
0,6 \%\end{array}$ & $\begin{array}{l}15,0 \% \\
64,3 \%\end{array}$ & $\begin{array}{l}0,0 \% \\
2,2 \%\end{array}$ & $\begin{array}{l}79,3 \% \\
32,9 \%\end{array}$ & $\begin{array}{l}5,7 \% \\
0,6 \%\end{array}$ & $\begin{array}{l}85,0 \% \\
33,5 \%\end{array}$ \\
\hline
\end{tabular}


Im Folgenden werden zunächst die privaten Briefe und dann die königlichen Stelentexte diachron veranschaulicht:

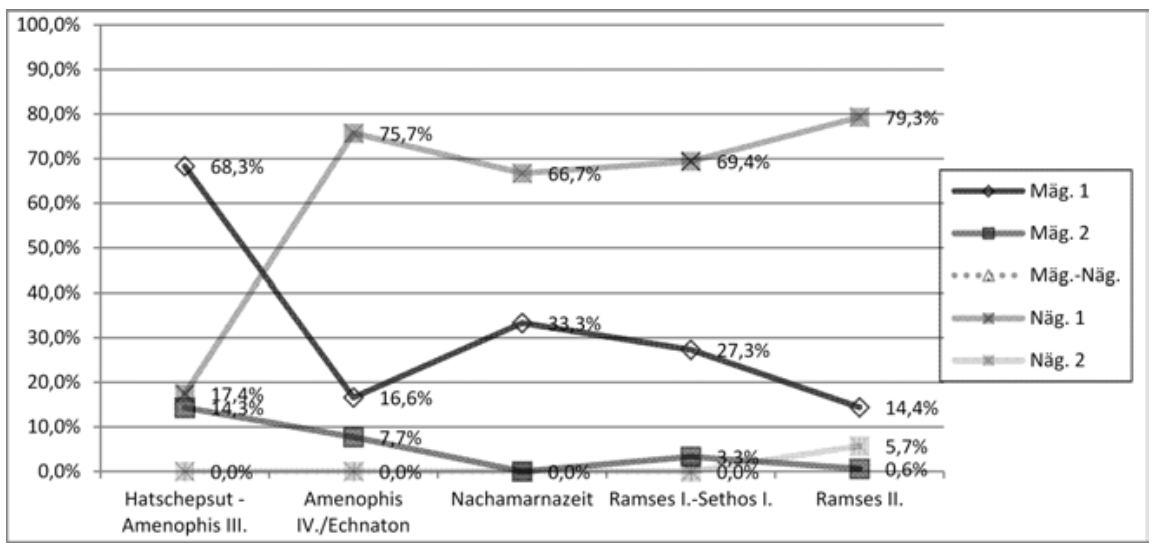

Abb. 16: Private Briefe von Amenophis III. (Hatschepsut-Amenophis II.) bis Ramses II.

Die Sprache der privaten Briefe entwickelt sich von einer Sprache mit vielen mittelägyptischen Formen (82,6\%) und wenigen Neuägyptizismen (17,4\%) in der zweiten Hälfte der 18. Dynastie zu einer, die zu 85,0\% neuägyptisch und zu nur noch 15,0 \% mittelägyptisch ist, in der Zeit Ramses' II. Es lässt sich in den privaten Briefen ein Umbruch in der Amarnazeit feststellen, der einerseits nur mit Vorsicht ernst zu nehmen ist, da die Beleglage in der Zeit Amenophis' III. sowie in der Nachamarnazeit nicht ausreichend ist. Andererseits zeigt der Konjunktiv als ein unter Amenophis III. und Echnaton gut belegtes Phänomen eine eindeutige Wende in der Sprachentwicklung. Dieser plötzliche Wandel in der Sprache kann unter Umständen auf einen Dialekt zurückgeführt werden. Sehr interessant ist ebenso, dass die hybride Sprachform in den privaten Briefen nicht belegt ist.

Die königlichen Stelentexte zeigen einen ganz anderen Verlaufsprozess als die Briefe (s. Abb. 17). Die Stelentexte Amenophis' III. zeigen eine $100 \%$ ige mittelägyptische Sprache, wie bei solchen Texten eigentlich nicht anders $z u$ erwarten. In der Zeit seines Sohnes und Nachfolgers Amenophis' IV./Echnatons ändert sich die Situation in den Texten seiner Grenzstelen in Tell el-Amarna radikal. Ihre Sprache ist $\mathrm{zu} 71,3 \%$ neuägyptisch, $\mathrm{zu} 7,1 \%$ hybrid und $\mathrm{zu}$ nur noch 21,6\% mittelägyptisch. Die Stelentexte aus anderen Orten weisen überhaupt keine neuägyptischen Neuerungen auf. Mit Ausnahme des HaremhabDekrets sind alle Texte auf den königlichen Stelen der Nachamarnazeit in mittelägyptischer Sprache abgefasst. Das Dekret selbst besteht aus 69,3\% mittel- 


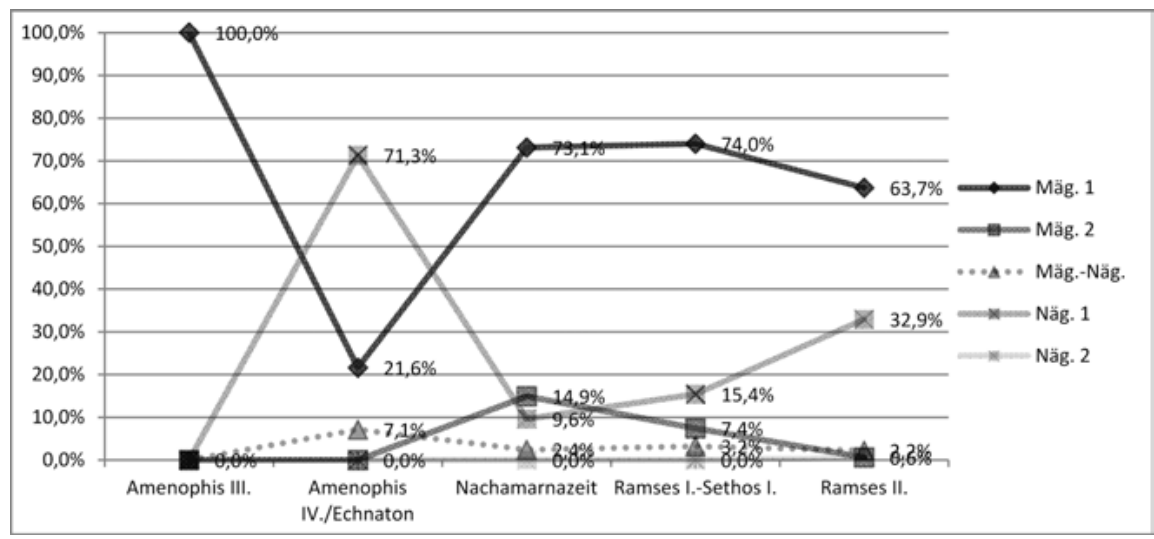

Abb. 17: Königliche Stelentexte von Amenophis III. bis Ramses II.

ägyptischen, 6,7\% hybriden und 24,0\% neuägyptischen Sprachformen. Zusammen mit dem Dekret zeigen die anderen Stelentexte, wie sehr die Schreiber der Nachamarnazeit der Anwendung der mittelägyptischen Sprache und Orthographie nicht mehr mächtig sind, wie z. B. im Fall des Konjunktivs im Haremhab-Dekret und der Negationspartikeln $n$ und $n n$ auf der Restaurationsstele. Abgesehen davon sind die königlichen Stelentexte in der Nachamarnazeit zu 88,0 \% mittelägyptisch, 2,4\% hybrid und 9,6\% neuägyptisch. Die Sprache der Stelentexte Ramses' I. und Sethos' I. beinhaltet einen nicht geringen Anteil an Neuägyptizismen (15,4\% neuägyptisch und 3,2\% hybrid), sie ist allerdings noch größtenteils mittelägyptisch $(81,4 \%)$. In den meisten königlichen Stelentexten Ramses' II. überwiegen mittelägyptische Sprachphänomene. Die dritte Gruppe von Texten allein weist aber einen mittelägyptischen Anteil von nur $55,1 \%$ auf, wobei $42,0 \%$ neuägyptische und 2,9\% hybride Bildungen vorkommen.

Gegen den möglichen Einwand, dass die Grenzstelen von Tell el-Amarna Dekrete sind, die sprachlich anders abgefasst werden, wird hier auf die Restaurationsstele verwiesen, deren Text auch als Dekret zu betrachten ist und trotzdem komplett aus mittelägyptischen Gefügen besteht. Andere Dekrettexte der folgenden Zeit enthalten zwar neuägyptische Sprachelemente, wie z. B. die Stelen von Haremhab, Nauri und Hermopolis, sie sind jedoch mehrheitlich mittelägyptisch. Noch auffälliger bei der Sprache der Grenzstelen von Tell el-Amarna ist die Einheitlichkeit. In den Texten kommen die Negationen $n$ und $n n$ sowie die zweite mittelägyptische Konjunktivform nie vor. Uneinheitlich ist jedoch die Anwendung der Personalsuffixe $=s n$ und $=w$ sowie der Possessivsuffixe und Possessivartikel; das Suffix $=w$ und die Possessivartikel treten allerdings zum größten Teil in der direkten Rede auf. 


\title{
5 Politik und Sprache
}

Ausgehend von der Tatsache, dass sich die Sprache der Grenzstelen von Tell el-Amarna einerseits von derjenigen der königlichen Stelentexte aus anderen Orten zur Amarnazeit und andererseits von derjenigen der königlichen Stelentexte der Vor- und Nachamarnazeit deutlich abhebt, werden im Folgenden die in der Literatur vertretenen Auffassungen über diese Sprache referiert, anhand der ausgeführten Statistiken beurteilt und die Vorstellungen über die Gründe, die hinter diesem Umbruch stecken können, erörtert.

Baines beschreibt die linguistische Situation wie folgt:

\begin{abstract}
The language of hieroglyphic inscriptions had evolved far from the conservative forms of the reign of Hatshepsut a century earlier, but the development was uneven and did not tend toward a reform. Inscriptions from the Amarna period show far more change, extending to some of the hieroglyphs used. What was written there was still far from the spoken language, as is shown by the speed at which written Late Egyptian developed thereafter, but a move straight to writing the vernacular - so far as such a thing is possible - was perhaps not conceivable. ${ }^{142}$
\end{abstract}

Nach Baines hat sich die Sprache der Stelen zur Amarnazeit also nur ansatzweise in Richtung der gesprochenen Sprache entwickelt. Worin die Differenz zur gesprochenen Sprache bestehen soll, wie sie sich in den Alltagstexten als der nächstmöglichen Verschriftlichung der gesprochenen Sprache niedergeschlagen hat, ${ }^{143}$ sagt Baines nicht. Unsere synchronen statistischen Analysen zeigen, dass die Sprache der königlichen Stelentexte von Tell el-Amarna an diejenige der privaten Briefe sehr nah ist, was vorher und nachher - außer in bestimmten Stelentexten Ramses' II. - nie der Fall ist.

Baines fügt dann hinzu: „Written language may have been an area where change was introduced almost for its own sake, without an intent that related closely to religious and political ideas." 144

Im Lichte unserer Überlegungen, zumindest in Bezug auf die Amarnazeit, ist das nicht plausibel. Die Sprache der königlichen Stelentexte in der Vorund Nachamarnazeit kann nicht als eine graduelle Entwicklung derjenigen der königlichen Stelentexte von Tell el-Amarna gesehen werden, und die Neuerun-

142 Baines (1998) 307.

143 In diesem Rahmen sind nur die neuen Briefformeln (Polis \& Winand (2010) 3f.) sowie die neuägyptischen Sprachformen wie der neuägyptische Konjunktiv und die Periphrase mit jrj zu erwähnen. Diese Sprachformen finden sowohl in den Alltagstexten als auch in den Dekorumstexten gleichzeitig Verwendung.

144 Baines (1998) 307. 
gen in diesen Texten werden größtenteils systematisch und einheitlich angewendet. Das spricht stark für eine absichtliche Reform.

Auch Quack möchte, in Anlehnung an Stricker, eher einen graduellen, nicht bewusst gesteuerten Sprachwandel sehen:

Die vulgäre Sprachform dagegen habe sich zum Neuägyptischen weiterentwickelt. Dabei betont Stricker mit Recht die graduelle Entwicklung und spricht sich gegen das Modell aus, Echnaton habe das Neuägyptische bewusst eingeführt, vielmehr liege in seiner Regierung nur die letzte Phase der Entwicklung. ${ }^{145}$

Richtig am graduellen Modell ist zwar, dass die Mehrheit der Neuägyptizismen, die in der Amarnazeit regelmäßig vorkommen, schon längst vor Echnaton belegt sind. Das ist allerdings nur sporadisch der Fall. Unter Echnaton erfuhr, wie die vorliegende Untersuchung zeigt, die sprachliche Entwicklung einen starken Schub.

Baines, Stricker und Quack schließen also eine bewusste Reform bzw. eine gezielte Einführung der Sprache durch den König aus.

Eine entgegengesetzte Meinung vertreten Polis \& Winand. Sie verfolgen in einem Artikel die ägyptische Sprachentwicklung von Anfang an und gehen dabei auf die Benutzung von Neuägyptizismen in der Voramarnazeit ein. Die Sprachsituation in der Amarnazeit beschreiben sie wie folgt:

La période amarnienne est régulièrement caractérisée comme le moment de toutes les innovations en Égypte ancienne - il n'y avait dès lors guère de raison pour que la sphère linguistique échappe à cette tendance. Pourtant, comme souvent lorsque l'on regarde les choses d'un peu près, il apparaît que cette époque n'a pas proprement innové en la matière, mais a plutôt cristallisé un certain nombre de traits qui s'étaient déjà révélés plus tôt au cours de l'évolution de la langue égyptienne à travers temps et registres d'expression. [...] Comme on peut le constater, il serait abusif de considérer que le néo-égyptien naît avec la période amarnienne. En revanche, c'est bien à cette époque que l'usage de ce nouvel idiome s'est étendu à des catégories de textes où il n'avait encore jusque-là jamais été utilisé. ${ }^{146}$

Diese Ansicht stimmt mit den Ergebnissen unserer Studie größtenteils überein. Polis \& Winand ${ }^{147}$ erläutern ihre Auffassung u. a. mit Sprachphänomenen wie dem Artikel, dem Possessivum, der Narrativen Sequenz, dem Umstandssatz, dem Ausfall des Infixes . $n(j w s \underline{d} m . n=f>s \underline{d} m=f)$ und den Negationen $b n$ und $b w$.

145 Quack (2013) 38; Stricker (1945) 32-36.

146 Polis \& Winand (2010) $1 ; 5$.

147 Polis \& Winand (2010) $5 \mathrm{f}$. 
Sie gehen davon aus, dass all diese Spracherscheinungen auch in den Alltagstexten der Voramarnazeit Verwendung finden. Das ist aber nicht ganz genau. Wie oben ausführlich gezeigt, sind einige neuägyptische Sprachformen bzw. ihre Gebrauchsweisen erst in der Amarnazeit überliefert. D. h. die neuägyptischen Sprachneuerungen entfalten sich in der Amarnazeit nicht nur quantitativ - regelmäßiges Vorkommen -, sondern auch qualitativ - Registerwechsel und neu verschriftlichte Prägungen bzw. neue Verwendungsweisen. Was die Rolle des Königs dabei betrifft, so fügen sie folgendes hinzu:

L'utilisation du néo-égyptien dans les différentes sphères de l'écrit sera définitivement légitimée sous Aménophis IV - Akhénaton. En effet, la révolution culturelle de l'époque amarnienne s'accompagne indéniablement d'une extension du néo-égyptien à des registres d'expression nouveaux: en dehors des lettres - où apparaissent, précisément à cette période, les premières occurrences de formules épistolaires qui seront d'usage à l'époque ramesside qui suit -, des sources documentaires et des textes juridiques, il est employé sur les monuments officiels émanant de l'autorité royale. ${ }^{148}$

Die Frage nach möglichen Gründen für diese Legitimierung und Einsetzung neuägyptischer Sprachformen in andere Sprachnormen durch die königliche Autorität beziehen Polis \& Winand in ihre Überlegungen nicht ein.

Weniger politische als geistes-, kunst- und religionsgeschichtliche Gründe vermuten Behnk, Helck und Allen hinter dem Amarna-Sprachwandel. Sie bringen die Sprache genauso wie alle anderen Lebensbereiche in der Amarnazeit mit abstrakten Begriffen wie „Wahrheit in der Religion“ und „der naturalistischen Richtung der Kunst““,149 „Gegenwart“150 sowie „emphasis on the present“ und „visible and tangible reality“ ${ }^{151}$ in Verbindung.

Behnk z. B. sieht die Übernahme der „Umgangssprache des täglichen Lebens“ in die religiösen und Dekorumstexte als Reaktion auf die Idee vom „Streben nach Wahrheit [...] in der Religion und der naturalistischen Richtung der Kunst“. 152

Helck betrachtet die „Gegenwart“ als den Leitgedanken Echnatons, nach dem sich „,alle Bereiche des Lebens“ ändern, und ergänzt: „Die von allen gesprochene Sprache wird auch geschrieben - und nicht eine traditionelle Schriftsprache künstlicher Bildung.“153

148 Polis \& Winand (2010) 3.

149 Behnk (1924) §1.

150 Helck (1986) 56.

151 Allen (1996) 4.

152 Behnk (1924) § 1.

153 Helck (1986) 56. 


\section{Allen findet in der Religion den Grund für alle Reformen der Amarnazeit:}

For all its revolutionary aspects, the Amarna Period of Egyptian history was traditional in one central aspect: each of its innovations was carried out in the name of - and in service to - religion. ${ }^{154}$

Die tägliche Aktivität des Sonnengottes und die tagtägliche Neuschaffung der Welt mit dessen Licht und Wärme sind die Basis der neuen Religion:

This focus on the present rather than the eternal is one of the hallmarks of the Amarna Period and one of the features that set it off most strongly from traditional Egyptian culture. [...] But it can be seen in other facets of Akhenaten's revolution as well: for example, in the adaption of writing to reflect the contemporary spoken language. [...] Together with the emphasis on the present, Akhenaten's religion also stressed visible and tangible reality at the expense of the unseen and the mysterious. ${ }^{155}$

Die Assoziation dieses Wandels in der Sprache mit solchen abstrakten Ideen ist allerdings nur hypothetischer Natur. In der Praxis lassen sie sich nicht verifizieren.

Sethe schließt die Übernahme des Neuägyptischen als Schriftsprache mit den religiösen und politischen Umwälzungen in der Amarnazeit zusammen:

Die Umwälzungen, die sich in diesen $1 \frac{1}{2}$ bis 2 Jahrzehnten im geistigen Leben der Ägypter vollzogen, haben auch das Gebiet der Sprache nicht unberührt gelassen. Die neuäg. Sprachformen haben damals vorübergehend auch in Kreise Eingang gefunden, die ihnen bisher verschlossen waren und auch später in der Regel wieder verschlossen geblieben sind, die Religion und die religiöse Literatur (Hymnen), sowie die offiziellen Denkmäler und die Titulaturen und Amtsbezeichnungen des Königs und der Staatsbehörden. ${ }^{156}$

\section{Darin folgen ihm Erman und Hintze. ${ }^{157}$ Den Grund sieht Sethe wie folgt:}

So wird man in der auf die Freiheitskriege gegen die Hyksos folgenden Aufschließung der Ägypter für eine weitere Welt, ihrer mehr universellen Einstellung, in der man ja auch eine Quelle für die universelle Sonnenreligion Amenophis' IV. hat finden wollen, die eigentliche treibende Kraft für die Ersetzung der alten Schriftsprache durch die gesprochene Volkssprache, das Neuägyptische, zu vermuten haben. ${ }^{158}$

154 Allen (1996) 3.

155 Allen (1996) 4.

156 Sethe (1925) 308.

157 Erman (1933) 1f.; Hintze (1947) 86.

158 Sethe (1925) $310 \mathrm{f}$. 
Diese Vermutung Sethes bewegt sich ähnlich wie die eben erwähnten Ausführungen von Behnk, Helck und Allen auf einer hypothetischen Ebene, die empirisch kaum zu begründen ist.

Silverman fasst den Wandel in der Sprache der Amarnazeit so auf:

The Motive for changes in Language, as in other areas, was less a desire for popular appeal than part of an elaborate plan to emphasize the divinity of the living king. An amalgam of classical literary forms with nonliterary and vernacular components, Akhenaten's language represented a distinct, almost artificial, literary style, one that differed from what preceded and what would succeed it. It focused on the king, demonstrating his uniqueness. [...] Akhenaten's amalgam does, however, bear some similarity to literary Late Egyptian, the language used in the composition of stories, and it may have served as an inspiration for this genre. ${ }^{159}$

Man mag darüber spekulieren, ob die Göttlichkeit des Königs durch die Zusammensetzung einer einzigartigen künstlichen Sprache betont werden sollte. Was die Komponenten dieser Sprache anbelangt, so wird Silverman Recht gegeben, dass sich die Sprache im Grunde auf die beiden hierarchisch niedrigen Sprachnormen stützt. Das bestätigen einerseits die synchronen Analysen in Bezug auf die privaten Briefe, andererseits die Verwendung des negativen präteritalen $b w$ $s \underline{d} m=f$ und des negativen Aoristes $b w s \underline{d} m=f$, die ab der Amarnazeit in den Alltags-, literarischen und Dekorumstexten zu finden sind, und des negativen Aoristes $b w s \underline{d m} . n=f$, das nur in den literarischen und Dekorumstexten vorkommen kann.

Goldwasser beurteilt die Übernahme der gesprochenen Alltagssprache in die offizielle Schriftsprache wie folgt:

In a decision rarely enacted, the dominating circles officially admitted forms belonging to the vernacular into the official texts of the culture. In contrast to the gradual and rather limited infiltration of the colloquial into texts written prior to this period, this appearance of the "spoken language" in the texts was clearly dictated by the ruling class: the king and his followers (Tobin 1986). For the first time in the history of the New Kingdom, the „vernacular“ was officially allowed into the aggregate of texts that formed the official repertoire-thereby canonizing a new set of syntactical forms. These forms are most noticeable in those items of the repertoire that had been previously inaccessible to the Late Egyptian undercurrents (official religious texts, royal eulogies, etc.). Reasons for these changes may be sought in the naturalistic/"positivistic" view in which Akhenaten perceived the world. Reality (as opposed to things magical, mythical, and cryptic), or more precisely, "everything that is embraced by the rays of the sun," is the structural condition for the real truth. Therefore, language variations (being the articulation of people acting

159 Silverman (1999) 154. 
under the above-mentioned condition) should be treated as a legitimate form of revealed truth. ${ }^{160}$

Ganz zu Recht hebt Goldwasser hervor, dass die Umgangssprache nur mit Genehmigung oder Verordnung des Königs und seiner Hofkreise in die höheren Normen gelangen kann. Die von Goldwasser dafür angegebenen Gründe sind jedoch wiederum hypothetisch.

Gemeinsam haben diese Meinungen - mit Ausnahme derer von Baines, Stricker und Quack -, dass sie die Änderungen in der offiziellen Schriftsprache mit dem König und seinen Reformen assoziieren. Es herrscht jedoch kein Konsens darüber, was die Ursachen für diese Entscheidung sein können. Die Mehrheit der angegebenen Gründe sind rein spekulativ und lassen sich weder bestätigen noch widerlegen.

Ein bedenkenswerter Beitrag stammt von Pflüger, der die grundlegende sprachliche Veränderung mit dem Verzicht Echnatons auf die alte Beamtenschaft und der Beförderung von Beamten niedrigen Ursprungs verbinden will. ${ }^{161}$ Diese Ansicht lässt sich einerseits mit sprachlichen Neuerungen - eventuell einem Dialekt - wie z. B. dem neuägyptischen Konjunktiv, der Umschreibung mit dem Hilfsverb jrj, dem regelmäßigen Gebrauch der Negationspartikeln $b w$ und $b n$ und der deutlich regulären Verwendung anderer Neuägyptizismen gut bestätigen, die sowohl in den privaten Briefen als auch den königlichen Stelentexten von Tell el-Amarna gleichzeitig auftauchen. Diese Innovationen kommen in der Voramarnazeit entweder überhaupt nicht, wie der neuägyptische Konjunktiv, der negative Aorist mit der Negation $b w$ und die Periphrase mit $j r j$ - mit Ausnahme einiger Belege mit jrj vor bestimmten Verbklassen oder sporadisch, wie alle anderen oben erwähnten Sprachphänomene, vor. Andererseits sprechen die königlichen Stelentexte außerhalb von Tell el-Amarna dafür, dass diese Reform auf Tell el-Amarna beschränkt ist.

Wie oben aufgeführt, ist es greifbar, dass die Gesellschaftsschicht von Tell el-Amarna grundsätzlich aus Militär- und anderen neuen Beamten besteht. ${ }^{162}$ Die Tatsache, dass mindestens vier „Rekrutenschreiber“ belegt sind, ${ }^{163}$ nämlich Maja, Ramose, Eje und Paatonemhab (= Haremhab), aber auch der „Wesir“ Nacht(paaton), der ausschließlich in Tell el-Amarna nachgewiesen ist und den möglichen Titel „,[Vorsteher (?)] der Schreiber/Inschriften auf Stein“ ([jm.j-r3 (?)] sḩw.w hr jnr) trägt, ${ }^{164}$ weist sehr deutlich darauf hin, dass diese neuen Hof-

160 Goldwasser (1992) 249; Hervorheb. i. O.

161 Pflüger (1994) 124-128.

162 Wilson (1951) 207; Kees (1953) 84-88; Kadry (1982) 79; Pflüger (1994) 124-126.

163 Helck (1964) 16; Kadry (1982) 59 und 76; zu den Militärschreibern s. Roccati (1992) $99 \mathrm{f}$.

164 Peet \& Woolley (1923) Taf. 7.4. Murnane (1995) 167 übersetzt „... writings on stone“. 
kreise die Sprache von Tell el-Amarna durch ihre Sprache geprägt haben dürften.

Was die Rolle des Königs dabei anbelangt, so ist es schwer festzumachen, ob sich die Schreiber von Tell el-Amarna der klassisch mittelägyptischen Sprache und Orthographie nicht bedienen konnten und sie deshalb - mit Zustimmung des Königs - die Dialektsprache benutzten oder ob es von Anfang an eine Entscheidung des Königs und seiner Beamten war, das Mittelägyptische als die traditionelle Schriftsprache $\mathrm{zu}$ verwerfen und sich der Alltagssprache zuzuwenden.

In den königlichen Stelentexten der Nachamarnazeit kommt ausschließlich - mit Ausnahme des Haremhab-Dekrets - das klassische Mittelägyptisch wieder zur Anwendung. Dies kann entweder damit zusammenhängen, dass in der Nachamarnazeit andere Hofkreise, so die Restaurationsstele, eingesetzt waren oder, dass dies als eine Entscheidung der Könige der Nachamarnazeit als Teil der Restauration zu betrachten ist. Wegen des Haremhab-Dekrets ist Baines der Ansicht, dass die Innovationen der Amarna-Sprache fortgesetzt wurden:

The point of departure for changes in decorum is the Amarna Period, and the parallelism between religious, artistic, and linguistic transformations confirms the significance of that episode. Whereas the religion and art of Amarna were largely rejected, its linguistic innovations had a more evident and immediate effect and may have been seen as less threatening to the cultural order. ${ }^{165}$

Es ist allerdings gefährlich, ausgehend von einem einzigen Dokument die ganze Regierungszeit Haremhabs zu beurteilen. Richtet man den Blick auf alle königlichen Dekorumstexte aus der Zeit Haremhabs, ${ }^{166}$ so wird sichtbar, dass diese Texte kaum Neuägyptizismen aufweisen. Für die Dekrete kommt eine andere Sprachnorm zur Anwendung, wie die Dekrete der folgenden Zeit sehr deutlich zeigen.

Die Sprache der Amarna-Zeit ist wohl ein thebanischer Dialekt, der mit Zustimmung oder Verordnung Echnatons in die offizielle Schriftsprache gelangen konnte. Für einen solchen Dialekt entscheiden wir uns aus verschiedenen Gründen: Die Personenkreise um den König Echnaton kommen größtenteils aus Thebais. Die Königsmutter Teje und die Mehrheit der Militärbeamten stammen nämlich aus Achmim, andere Beamten und Arbeiter aus Theben. Die sprachlichen Erscheinungen, die oben behandelt wurden, sind im thebanischen Raum entweder entstanden oder zuerst belegt. ${ }^{167}$

165 Baines (1996) 173; zum Haremhab-Dekret vgl. ibid. $165 \mathrm{f}$.

166 Helck (1958) 2113-2139.

167 Vgl. Loprieno (1982) 82. 


\section{Zusammenfassung}

In diesem Artikel ging es darum, die Wende in der Sprache der Amarnazeit zu zeigen und die Rolle des Königs als des ersten Staatsmannes dabei herauszufinden. Zunächst wurden das politische System und die Verwaltungsapparatur im Ägypten - vor allem - der 18. und Anfang der 19. Dynastie, kurz skizziert. Es zeigte sich, dass sich im Lande ab etwa der zweiten Hälfte der 18. Dynastie zwei große „Parteien“ bildeten, die um die Macht kämpften: Auf der einen Seite standen der König und seine begünstigten Militärbeamten sowie die neuen Beamten niederer Herkunft. Und auf der anderen Seite war der „Klerus“ des Reichsgottes Amun, der Ämter an Kinder übertrug und allmählich Geltung und Macht gewann. Die Konfliktsituation verschärfte sich unter Amenophis IV./ Echnaton. Mit Hilfe seiner neuen Beamten gelang es ihm, die Amun-Priesterschaft zu beseitigen, die Residenz nach Achetaton zu verlegen und diverse radikale Reformen durchzuführen. In der Nachamarnazeit wurde der Amun-Kult wiederhergestellt, und die Söhne der alten Beamtenfamilien - wenn man dem Text der Restaurationsstele glauben mag - besetzten wieder die einflussreichen Positionen.

In einem weiteren Punkt wurde die Sprachentwicklung vom Mittel- zum Neuägyptischen verfolgt. Es wurde sichtbar, dass dieser Wandlungsprozess sehr verzahnt ist. In Bezug auf die Amarnazeit zeigte sich, dass eine der Sprachentwicklungsphasen in der Zeit Amenophis' IV/Echnatons beginnt.

Anhand der statistischen Analysen wurde eine Umwälzung sowohl in der Sprache der privaten Briefe als auch in derjenigen der königlichen Stelentexte von Tell el-Amarna nachgewiesen. Die Sprache der privaten Briefe ist wohl von einem thebanischen Dialekt geprägt. Die Sprache der königlichen Stelentexte ist entweder mit den Hofkreisen von Tell el-Amarna zu verbinden, die die mittelägyptische Sprache und Orthographie wahrscheinlich nicht handhaben konnten und mit Genehmigung des Königs ihre Dialektsprache benutzten. (Die Schreiber der Nachamarnazeit, die zu dem alten Beamtenapparat gehörten, griffen dann auf die klassische Sprache zurück.) Oder es könnte sein, dass es Echnaton und seine Beamtenschaft waren, die den Beschluss fassten, die Sprache zu reformieren und diese Dialektsprache in die offizielle Schriftsprache zu übernehmen, und dass es die Könige der Nachamarnazeit waren, die den Rückgriff auf das Mittelägyptische als Teil der Restauration betrachteten. Auf jeden Fall sind diese Sprachwechsel nicht geistes-, kunst- oder religionsgeschichtlich bedingt, sondern als politische Akte zu deuten. 


\section{Literaturverzeichnis}

Aling, Charles F. (1984): A Prosopographical Study of the Reigns of Thutmosis IV and Amenhotep III. Ann Arbor: University Microfilms International.

Allam, Schafik (1987): „Trois missives d’un commandant (Pap. CGC 58053-5)“. Annales du service des antiquités de l'Égypte 71, 4-25.

Allen, James P. (1996): „The Religion of Amarna“. In: Dorothea Arnold (Hg.), The Royal Women of Amarna: Images of Beauty from Ancient Egypt. New York: Metropolitan Museum of Art, 3-5

Allen, James P. (2010): „Language, Scripts and Literacy“. In: Alan B. Lloyd (Hg.), A Companion to Ancient Egypt, Vol. II. Malden: Wiley-Blackwell, 641-662.

Anthes, Rudolf (1931): „Der Wesir Paser als Hohepriester des Amon in Hermonthis“. Zeitschrift für ägyptische Sprache und Altertumskunde 67, 2-9.

Badawi, Ahmed (1948): Memphis als zweite Landeshauptstadt im Neuen Reich. Kairo: Institute Français d'Archéologie Orientale.

Baines, John (1996): „Classicism and Modernism in the Literature of the New Kingdom“. In: Antonio Loprieno (Hg.), Ancient Egyptian Literature: History and Forms. Leiden [u. a.]: Brill, 157-174.

Baines, John (1998): „The Dawn of the Amarna“. In: David B. O’Connor \& Eric H. Cline (Hgg.), Amenhotep III: Perspectives on His Reign. Michigan: University of Michigan Press, 271312.

Behnk, Frida (1924): Grammatik der Texte aus El Amarna. Berlin: Geuthner.

Brose, Marc (2014): Grammatik der dokumentarischen Texte des Mittleren Reiches. Hamburg: Widmaier. (Lingua Aegyptia Studia Monographica, 13)

Bryan, M. Betsy (2006): „Administration in the Reign of Thutmose III“. In: David B. O'Connor \& Eric H. Cline (Hgg.), Thutmose III: A New Biography. Michigan: University of Michigan Press, 69-122.

Caminos, Ricardo A. (1954): Late-Egyptian Miscellanies. London: Oxford University Press.

Caminos, Ricardo A. (1963): „Papyrus Berlin 10463“. Journal of Egyptian Archaeology 49, 29-37.

Černý, Jaroslav \& Sarah Israelit-Groll (1993): A Late Egyptian Grammar. Rom: Editrice Pontificio Istituto Biblico.

Clère, Jacques J. (1956): „L’ancienneté des négations à b initial du néo-égyptien“. Mitteilungen des Deutschen Archäologischen Instituts 14, 29-33.

David, Arlette (2006): Syntactic and Lexico-semantic Aspects of the Legal Register in Ramesside Royal Decrees. Wiesbaden: Harrassowitz. (GOF IV, Reihe Ägypten 38)

Davis, Virginia L. (1973): Syntax of the Negative Particles bw and bn in Late Egyptian. München: Deutscher Kunstverlag. (Münchener Ägyptologische Studien 29)

Demarée, Robert J. (1999): „A Letter of Reproach“. In: Emily Teeter \& Edward F. Wente (Hgg.), Gold of Praise. Studies on Ancient Egypt in Honor of Edward F. Wente. Chicago: Oriental Institute, 75-82. (Studies in Ancient Oriental Civilisation 58)

Dodson, Aidan M. (2009): Amarna sunset: Nefertiti, Tutankhamun, Ay, Horemheb, and the Egyptian Counter-Reformation. Kairo: American University in Cairo Press.

Downes, Dorothy (1974): The Excavations at Esna 1905-1906. Warminster: Aris \& Phillips Limited.

Edel, Elmar (1955/1964): Altägyptische Grammatik I/II. Rom: Pontificium Institutum Biblicum. Edel, Elmar (1959): „Die Herkunft des neuägyptisch-koptischen Personalsuffixes der 3. Person Plural -w“. Zeitschrift für ägyptische Sprache und Altertumskunde 84, 17-38. 
Edel, Elmar (1983): „Der ägyptisch-hethitische Friedensvertrag zwischen Ramses II. und Hattusili III.“. In: Rykle Borger (Hg.), Texte aus der Umwelt des Alten Testaments I.2. Gütersloh: Verlagshaus Mohn, 135-153.

Eichler, Selke S. (2000): Die Verwaltung des „Haus des Amun“ in der 18. Dynastie. Hamburg: Buske (Studien zur altägyptischen Kultur, Beiheft 7)

El-Hamrawi, Mahmoud (2006): „The synthetic $b w$ s $\underline{d} m=f, b w$ s $\underline{d}$ m.t $f f$ and $b w s \underline{d m} . n=f$ as transitional verbal forms of $n s \underline{d} m=f, n s \underline{d} m . t=f$ and $n s \underline{d} m . n=f$ of Middle Egyptian to periphrastic bw pu=f $s \underline{d} m$, bw ir.t=f $s \underline{d} m$ and $b w$ ir=f $s \underline{d} m$ of Late Egyptian“. Bulletin de la Société d'Archéologie Copte 45, 81-94.

El-Hamrawi, Mahmoud (2007): „The negative particles $n, m, b w$ and $\mu \pi \varepsilon$ as features of dialects in Ancient Egyptian Language“. Bulletin de la Société d’Archéologie Copte 46, 31-60.

El-Sayed, Ramadan (1979): „Quelques précisions sur l'histoire de la province d'Edfou à la 2e période intermédiaire“. Bulletin de l'Institut Français d'Archéologie Orientale 79, 167207.

Erman, Adolf (1933): Neuägyptische Grammatik. Leipzig: Engelmann. (Nachdruck 1995. Hildesheim [u. a.]: Olms)

Fischer, Henry G. (2006): „Marginalia/4“. Göttinger Miszellen 210, 23-37.

Frandsen, Paul J. (1974): An Outline of the Late Egyptian Verbal System. Kopenhagen: Akademisk Forlag.

Franke, Detlef (2002): „Theben und Memphis - Metropolen im Alten Ägypten“. In: Michael Jansen (Hg.), Entstehung und Entwicklung von Metropolen. 4. Symposium, Bonn, 20.-23. 06. 1996. Aachen: IAS, 7-20.

Frankfort, Henri \& John D. S. Pendlebury (1933): The City of Akhenaten II: The North Suburb and the Desert Altars, The Excavations at Tell el Amarna during the Seasons 1926-1932. London: Oxford University Press. (Egypt Exploration Society 40)

Gardiner, Alan H. \& Kurt Sethe (1928): Egyptian Letters to the Dead: Mainly from the Old and Middle Kingdoms. London: Egypt Exploration Society.

Gardiner, Alan H. (1928): „An Egyptian Split Infinitive and the Origin of the Coptic Conjunctive Tense“. Journal of Egyptian Archaeology 14, 86-96.

Gardiner, Alan H. (1957): Egyptian Grammar: Being an Introduction to the Study of Hieroglyphs, Third Edition. Oxford: Griffith Institute.

Glanville, Stephen R. K. (1928): „The Letters of Aaḥmōse of Peniati“. Journal of Egyptian Archaeology 14, 297-305.

Goldwasser, Orly (1992): „Literary Late Egyptian as a Polysystem“. Poetics Today 13.3, 447462.

Goldwasser, Orly (1999): „'Low’ and 'High’ Dialects in Ramesside Egyptian“. In: Stefan Grunert (Hg.), Textcorpus und Wörterbuch: Aspekte zur ägyptischen Lexikographie. Leiden [u. a.]: Brill, 311-328.

Gundlach, Rolf (2004): „Vom Ende Amenophis’ II. bis zur Volljährigkeit Amenophis’ III.: Die Wende von der Außenpolitik zur Innenpolitik in der frühen Voramarnazeit im Spiegel der Königsideologie“. In: Rolf Gundlach \& Andrea Klug (Hgg.), Das ägyptische Königtum im Spannungsfeld zwischen Innen- und Außenpolitik im 2. Jahrtausend v. Chr. Wiesbaden: Harrassowitz, 119-219. (Königtum, Staat und Gesellschaft früher Hochkulturen 1)

Gunn, Battiscombe G. (1924): Studies in Egyptian Syntax. Paris: Librairie Orientaliste Paul Geuthner. (Nachdruck 2012. Oxford Griffith Institute) 
Gunn, Battiscombe G. (1929): „A Middle Kingdom Stela from Edfu“. Annales du service des antiquités de l'Égypte 29, 5-14.

Hassan, Selim (1975): Mastabas of Ny-'ankh-Pepy and Others, Excavations at Saqqara 19371938, Vol. II. Kairo: General Organisation for Government Printing Offices.

Helck, Wolfgang (1955): Urkunden der 18. Dynastie: Historische Inschriften Thutmosis' III. und Amenophis' II. Berlin: Akademie-Verlag.

Helck, Wolfgang (1957a): Urkunden der 18. Dynastie: Historische Inschriften Thutmosis' IV. und Biographische Inschriften seiner Zeitgenossen. Berlin: Akademie-Verlag.

Helck, Wolfgang (1957b): Urkunden der 18. Dynastie: Historische Inschriften Amenophis' III. Berlin: Akademie-Verlag.

Helck, Wolfgang (1958): Urkunden der 18. Dynastie: Inschriften der Könige von Amenophis III. bis Haremhab und ihrer Zeitgenossen. Berlin: Akademie-Verlag.

Helck, Wolfgang (1964): Der Einfluss der Militärführer in der 18. ägyptischen Dynastie. Hildesheim: Olms. (Untersuchungen zur Geschichte und Altertumskunde Ägyptens 14)

Helck, Wolfgang (1971): Die Beziehungen Ägyptens zu Vorderasien im 3. und 2. Jahrtausend v. Chr. Wiesbaden: Harrassowitz.

Helck, Wolfgang (1986c): Politische Gegensätze im alten Ägypten. Hildesheim: Gerstenberg. (Hildesheimer ägyptologische Beiträge 23)

Hintze, Fritz (1947): „Die Haupttendenzen der ägyptischen Sprachentwicklung“. Zeitschrift für Phonetik und allgemeine Sprachwissenschaft 1.3, 85-108.

Israeli, Shlomit (1981-1982): „A Grammatical Analysis of the first 23 Pages of the El Amarna Texts: Bibliotheca Aegyptiaca VIII“. In: Sarah Groll (Hg.), Papers for Discussion. Presented by the Department of Egyptology, The Hebrew University, Jerusalem, Vol. I. Jerusalem: Department of Egyptology, Hebrew University, 279-304.

Jansen-Winkeln, Karl (1994): Text und Sprache in der 3. Zwischenzeit: Vorarbeiten zu einer spätmittelägyptischen Grammatik. Wiesbaden: Harrassowitz. (Ägypten und Altes Testament 26)

Junge, Friedrich (1984): „Sprache“. In: Wolfgang Helck \& Eberhard Otto (Hgg.), Lexikon der Ägyptologie, Bd. V. Wiesbaden: Harrassowitz, Sp. 1176-1211.

Junge, Friedrich (1985): „Sprachstufen und Sprachgeschichte“. Zeitschrift der Deutschen Morgenländischen Gesellschaft, Supplement VI, 17-34.

Junge, Friedrich (2008): Einführung in die Grammatik des Neuägyptischen, 3., verb. Aufl. Wiesbaden: Harrassowitz.

Kadry, Ahmed (1982): Officers and Officials in the New Kingdom. Budapest: Loránd Eötvös University. (Studia Aegyptiaca, VIII)

Kahl, Jochem (1994): Das System der ägyptischen Hieroglyphenschrift in der 0.-3. Dynastie. Wiesbaden: Harrassowitz. (Göttinger Orientforschungen, IV. Reihe: Ägypten)

Kahl, Jochem (2002): Frühägyptisches Wörterbuch, 3 Bde. Wiesbaden: Harrassowitz.

Kees, Hermann (1953): Das Priestertum im ägyptischen Staat, vom Neuen Reich bis zur Spätzeit. Leiden[u. a.]: Brill.

Kessler, Dieter (2012): „Die juristische Relevanz der Tilgung des Amunnamens durch Echnaton“. In: Jochen Hallof (Hg.), Auf den Spuren des Sobek: Festschrift für Horst Beinlich zum 28. Dezember 2012. Dettelbach: Röll, 163-172. (Studien zu den Ritualszenen altägyptischer Tempel 12)

Kitchen, Kenneth A. (1975): Ramesside Inscriptions: Historical and Biographical I. Oxford [u. a.]: Blackwell.

Kitchen, Kenneth A. (1979): Ramesside Inscriptions: Historical and Biographical II. Oxford [u. a.]: Blackwell. 
Kitchen, Kenneth A. (1980): Ramesside Inscriptions: Historical and Biographical III. Oxford [u. a.]: Blackwell.

Kitchen, Kenneth A. (1983): Ramesside Inscriptions: Historical and Biographical V. Oxford [u. a.]: Blackwell.

Kitchen, Kenneth A. (1989): Ramesside Inscriptions: Historical and Biographical VII. Oxford [u. a.]: Blackwell.

Klug, Andrea (2002): Königliche Stelen in der Zeit von Ahmose bis Amenophis III. Turnhout: Brepols.

Koenig, Yvan (2004): „Le papyrus de Moutemheb“. Bulletin de l'institut français d'archéologie orientale 104, 291-326.

Korostovcev, Michail A. (1973): Grammaire du néo-égyptien. Moskau: Naouka.

Krause, Martin (1980): „Koptische Sprache“. In: Wolfgang Helck \& Eberhard Otto (Hgg.), Lexikon der Ägyptologie, Bd. III. Wiesbaden: Harrassowitz, Sp. 731-737.

Krauss, Rolf (1997): „Zur Chronologie der Nachfolger Achenatens unter Berücksichtigung der DOG-Funde aus Amarna“. Mitteilungen der Deutschen Orientgesellschaft 129, 225-250.

Kroeber, Burkhart (1970): Die Neuägyptizismen vor der Amarnazeit: Studien zur Entwicklung der ägyptischen Sprache vom Mittleren zum Neuen Reich. Tübingen: Eberhard-KarlsUniversität zu Tübingen.

Kruchten, Jean-Marie (1999): „From Middle Egyptian to Late Egyptian“. Lingua Aegyptia 6, 1-97.

Ladynin, Ivan A. \& Alexandre A. Nemirovsky (2010): "Year 12 of Akhenaten in the Context of the Near Eastern Political and Military History". Cultural Heritage of Egypt and Christian Orient 5, 143-164 (online 1-13). Online verfügbar unter: https://www.academia.edu/ 311613/Year_12_of_Akhenaten_in_the_Context_of_the_Near_Eastern_Political_and_ Military_History (Stand 03.10. 2016).

Loprieno, Antonio (1982): „Methodologische Anmerkungen zur Rolle der Dialekte in der ägyptischen Sprachentwicklung“. Göttinger Miszellen 53, 75-95.

Loprieno, Antonio (1995): Ancient Egyptian: A Linguistic Introduction. Cambridge: Cambridge University Press.

Meltzer, Edmund S. (1980): „Dialect Features in Middle Kingdom Inscriptions“. Newsletter of the American Research Center in Egypt 112, 34-36.

Murnane, William J. \& Charles C. van Siclen (1993): The Boundary Stelae of Akhenaten. London [u. a.]: Kegan Paul International.

Murnane, William J. (1995): Texts from the Amarna Period in Egypt. Atlanta: Scholars Press.

Nagai, Masakatsu (2006): „Language Variety in the 19th dynasty“. Lingua Aegyptia 14, 223-232.

Peet, Thomas E. \& Leonard C. Woolley (1923): The City of Akhenaten I: Excavations of 1921 and 1922 at El- 'Amarneh. London: Offices of the Egypt Exploration Society. (Egypt Exploration Society 38)

Peet, Thomas E. (1926): „Two Eighteenth dynasty letters. Papyrus Louvre 3230“. Journal of Egyptian Archaeology 12, 70-74.

Peet, Thomas E. (1930): „Two Letters from Akhetaten“. Annals of Archaeology and Anthropology 17, 88-91.

Pendlebury, John D. S. (1951): The City of Akhenaten III: The Central City and the Official Quarters. The Excavations at Tell el-Amarna during the Seasons 1926-1927 and 19311936, Vol. 1-2. London: Offices of the Egypt Exploration Society. (Egypt Exploration Society 44) 
Pflüger, Kurt (1994): „Beiträge zur Amarnazeit“. Zeitschrift für ägyptische Sprache und Altertumskunde 121, 123-132.

Polis, Stéphane \& Jean Winand (2010): “Les langues égyptiennes à l'époque amarnienne: Point de révolution sous le soleil d'Aton“. Culture, le magazine culturel de l'Université de Liège April 2010. Online verfügbar unter http://orbi.ulg.ac.be/handle/2268/58518 (Stand 03.10. 2016)

Quack, Joachim F. (2013): „Von der Vielfalt der ägyptischen Sprache“, Zeitschrift für ägyptische Sprache und Altertumskunde 140, 36-53.

Roccati, Alessandro (1992): „Der Schreiber“. In: Sergio Donadoni (Hg.), Der Mensch des Alten Ägypten, Frankfurt: Campus, 79-107.

Sandman, Maj (1938): Texts from the Time of Akhenaten. Brüssel: Édition de la Fondation Égyptologique Reine Élisabeth. (Bibliotheca Aegyptiaca VIII)

Schlögl, Hermann A. (2008): „Ägypten vor der Gründung von Amarna“. In: Christian Tietze (Hg.), Amarna: Lebensräume - Lebensbilder - Weltbilder. Echnaton und Amarna Wohnen im Diesseits, Ausstellung im Römisch-Germanischen Museum der Stadt Köln, 31. Mai bis 26. Oktober 2008; ein Projekt des Römisch-Germanischen Museums der Stadt Köln und der Universität Potsdam. Potsdam: Universitätsverlag, 16-33.

Schneider, Thomas (1994): Lexikon der Pharaonen: Die altägyptischen Könige von der Frühzeit bis zur Römerherrschaft. Zürich: Artemis.

Sethe, Kurt (1906): Urkunden der 18. Dynastie: Historisch-biographische Inschriften. Leipzig: Hinrichs.

Sethe, Kurt (1907): Urkunden der 18. Dynastie: Historisch-biographische Urkunden aus der Zeit Thutmosis' III. Leipzig: Hinrichs.

Sethe, Kurt (1925): „Das Verhältnis zwischen Demotisch und Koptisch und seine Lehren für die Geschichte der ägyptischen Sprache“. Zeitschrift der Deutschen Morgenländischen Gesellschaft 79, 290-316.

Shirley, J. J. (2013): „Crisis and Restructuring of the State: From the Second Intermediate Period to the Advent of the Ramesses“. In: Juan C. Moreno García (Hg.), Ancient Egyptian Administration. Leiden [u. a.]: Brill. (Handbuch der Orientalistik 104)

Silverman, David P. (1991): „Texts from the Amarna period and their position in the development of Ancient Egyptian“. Lingua Aegyptia 1, 301-314.

Silverman, David P. (1999): „The Spoken and Written Word“. In: Rita E. Freed \& Yvonne J. Markowitz \& Sue H. D'Auria (Hgg.), Pharaohs of the Sun: Akhenaten, Nefertiti, Tutankhamen. London: Kmt Communications, Inc, 151-155.

Silverman, David P. \& Josef W. Wegner \& Jennifer R. Houser Wegner (2006): Akhenaten and Tutankhamun: Revolution and Restoration. Philadelphia: University of Pennsylvania Museum of Archaeology and Anthropology.

Spiegelberg, Wilhelm (1920): „Neue Schenkungsstelen über Landstiftungen an Tempel“. Zeitschrift für ägyptische Sprache und Altertumskunde 56, 55-56.

Stadelmann, Rainer (1988): „Königliche Votivstelen aus dem Torraum des Totentempels Sethos' I. in Gurna“. Mitteilungen des Deutschen Archäologischen Instituts Kairo 44, 255-274.

Stricker, Bruno H. (1945): De Indeeling der egyptische taalgeschiedens. Leiden: (Oudheidkundige Mededelingen uit het Rijksmuseum van Oudheden te Leiden, 25)

Von Beckerath, Jürgen (1975): „Eje“. In: Wolfgang Helck \& Eberhard Otto (Hgg.), Lexikon der Ägyptologie, Bd. I. Wiesbaden: Harrassowitz, Sp. $1211 \mathrm{f}$.

Von Beckerath, Jürgen (1977): „Haremhab“. In: Wolfgang Helck \& Eberhard Otto (Hgg.), Lexikon der Ägyptologie, Bd. II. Wiesbaden: Harrassowitz, Sp. 962-964. 
Von Beckerath, Jürgen (1997): Chronologie des pharaonischen Ägypten: Die Zeitbestimmung der ägyptischen Geschichte von der Vorzeit bis 332 v. Chr. Mainz: von Zabern. (Münchner Ägyptologische Studien 46)

Wente, Edward F. (1990): Letters from Ancient Egypt. Atlanta: Scholars Press. (Writings from the Ancient World, 1)

Wilson, John A. (1951): The Burden of Egypt: An Interpretation of Ancient Egyptian Culture. Chicago: University of Chicago Press.

Winand, Jean (1992): Études de néo-égyptien I: La morphologie verbale. Lüttich: CIPL. TLA = http://aaew.bbaw.de/tla/index.html (Stand 03.10. 2016). 